\title{
An Attempt to Evaluate Accuracy of Diameter of Shallow Blind Holes Drilled in Solid Wood
}

\author{
Bolesław Porankiewicz \\ Poznan University of Technology \\ Piotrowo 3, 60-965 Poznań, Poland \\ E-mail: poranek@amu.edu.pl
}

Received: 07 July 2014; revised: 13 March 2015; accepted: 13 March 2015; published online: 23 March 2015

\begin{abstract}
The paper examines accuracy of low depth, blind holes drilled in a solid wood. Evaluated were statistical dependencies of the exponential form with several double interactions, between shift of average hole diameter series $d N$ and dispersion of holes diameter $D_{H}$ and parameters of Machine-Tool-Working element (M-T-W) set by drilling solid wood. Significant, nonlinear dependencies of the shift of average hole diameter series $d N$ and dispersion of holes diameter $D_{H}$ from height of centering spike $h_{C S}$, drill lateral stiffness $E_{L}$, drill bit diameter $D_{D}$, radial run out of main cutting edge $R_{R}$ were found.
\end{abstract}

Key words: drill bit, hole diameter shift, dispersion of holes diameter, drilling parameters, solid wood, drilling machine

\section{INTRODUCTION}

Increasing demand on high quality products in wood industry has also forced an increase of dimensional accuracy of wood machining. Dimensional accuracy of drilling processes, described by the shift of average hole diameter series $d N$ and the dispersion of holes diameter $D_{H}$ is one of criteria of machining quality. In the literature, however, no quantitative relationship between the $d N$ and the $D_{H}$ and parameters of M-T-W set by drilling wood has been developed yet. Instead of dimensional accuracy, edge quality of holes drilled in wood and wood-based materials was recently the subject of interest [1]. Because of limited stiffness of both tool (typically smaller for closed cutting, in direction perpendicular to tools side surfaces) and work piece, changes in side forces dependent from actual cutting conditions, generate deviations of their mutual position, which results in cutting inaccuracies [4]. This is the reason that parameters describing the M-T-W set influence dimensional accuracy of the drilling process. Dimensional accuracy is important in case of fitted dimensions, especially for mixed and fixed glued connections. Studies in this field were contributory, according to an assumption about the existence of machining tolerances. Parameters describing actual drilling conditions were not taken into consideration. Machining accuracy was evaluated as an average value of hole diameter and standard deviation for undefined cutting conditions. This assumption was employed in works aimed at creation of a limits and fits system for wood industry $[3,5,6]$. It should be noted that widespread scarcity in the works on woodworking is not determining cutting parameters.

The present study attempts to evaluate quantitative dependencies of shallow blind holes diameter accuracy, defined by the shift of average hole diameter from nominal dimension $d N$ and the dispersion of holes diameter $D_{H}$, upon parameters describing M-T-W set during drilling solid wood.

\section{EXPERIMENTAL}

The holes were drilled in wood of Scotch pine (Pinus sylvesrtis), with the use of a multi-spindle drilling machine (type DCWGW), and a horizontal milling and drilling machine (type DWJA). Experiments were done by vertical position of the DCWGW 19 working unit. The horizontal oscillations of the DWJA working unit was blocked. 


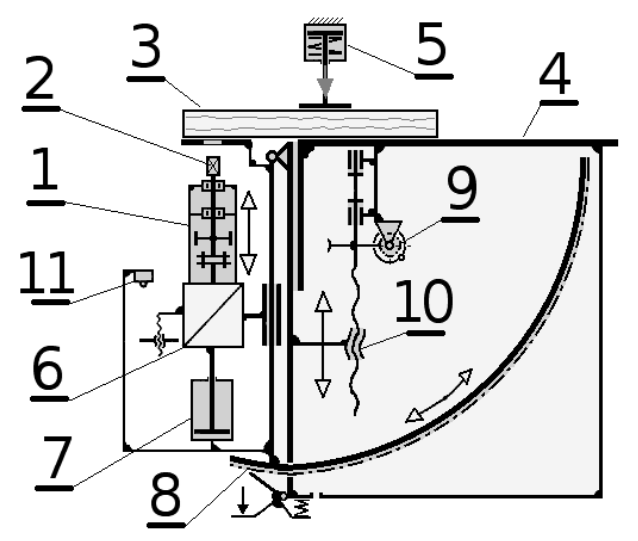

Fig. 1. Scheme of the multi-spindle drilling machine DCWGW 19; 1 - working unit, 2 - drill bit, 3 - working element, 4 - working table, 5 - air cylinders, 6 - electrical motor, 7 - working unit feed air cylinder, 8 - latch mechanism, 9 - snail gear box, 10 - screw mechanism, 11 - end switch

For drilling experiments a random level of independent variables was assumed. New drill bits as well as ones after multiples sharpening were used:
- with and without a centering spike,

- with and without side edges,

- short and long bits, having high and low stiffness $E_{L}$,

- small and large diameter $D_{D}$,

- with and without main cutting edge bevel angle $B_{A}$,

- with a different flute lead angle (maximum rake angle $\left.G_{F}\right)$,

- with different tangential $S_{T T}$ and axial $S_{R T}$ side surfaces taper angle,

- with a spiral and straight flute,

- with a cylindrical grip as well as a centering spike together with mounting thread.

The holes were drilled perpendicularly to wide surface of wood specimen, in transversal direction towards wood grains. The following parameters, typical for such drilling operation, were applied. Minimum, average and maximum values were given.

Machining parameters:

- spindle rotational speed $n\langle 2880 ; 6268 ; 10000\rangle \min ^{-1}$,

- feed per revolution $f_{R}=0.6 \mathrm{~mm}$,

- depth of drilled hole $H_{O}=12 \mathrm{~mm}$.

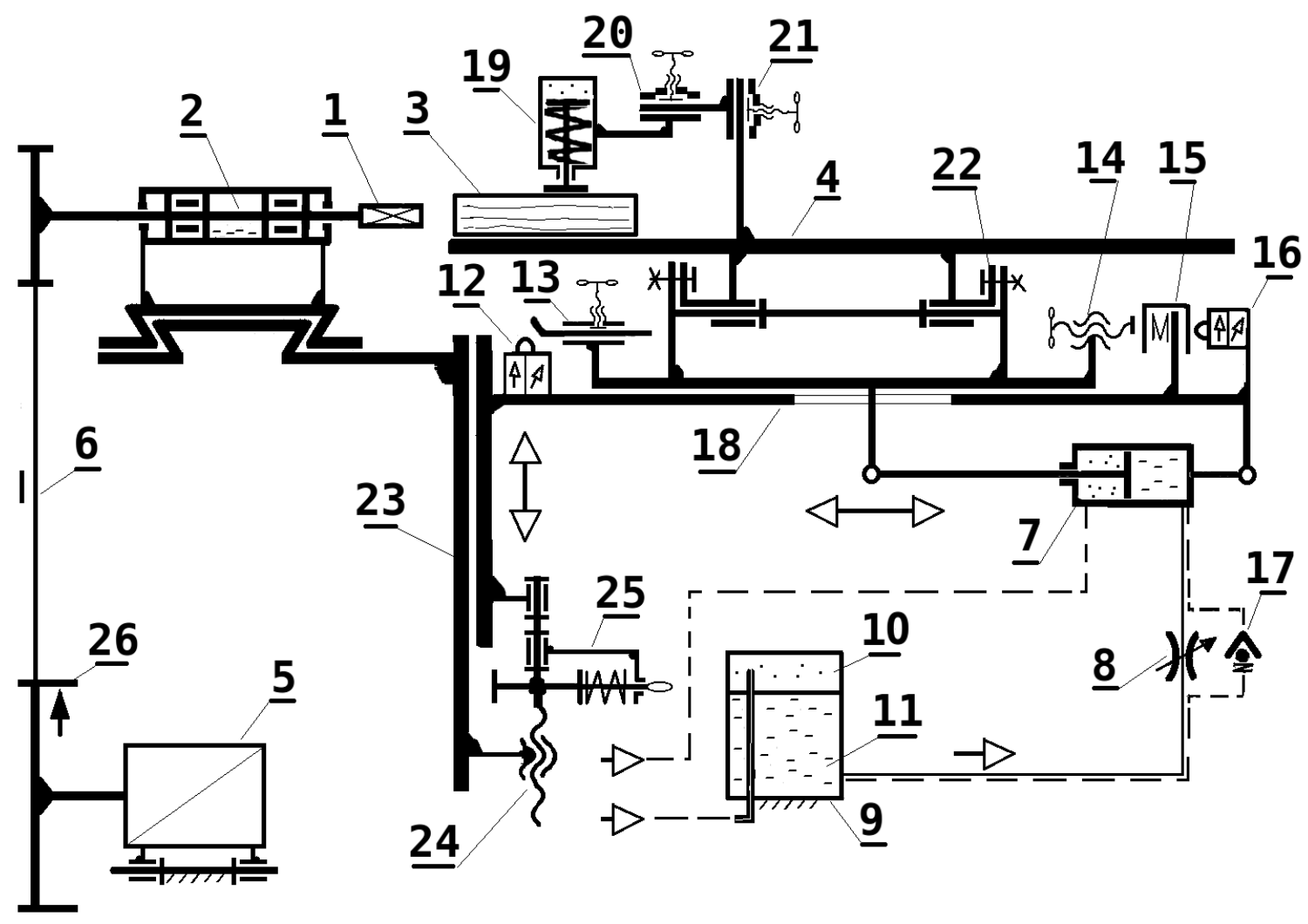

Fig. 2. Scheme of the milling - drilling machine DWJA; 1 - drilling bit, 2 - tool spindle, 3 - working element, 4 - working table, 5 electrical motor, 6 - belt transmission, 7 - hydraulic - pneumatic cylinder, 8 - throttle valve, 9 - hydraulic - pneumatic reservoir, 10 - air, 11 - oil, 12 - end switch, 13 - adjustable cam, 14 - adjustable back stop, 15 - bumper, 16 - back stop switch, 17 - reversible valve, 18 - horizontal working table support, 19 - single acting fixing air cylinder, 20 - horizontal adjusting and fixing mechanism, 20 - vertical adjusting and fixing mechanism, 22 - table turn mechanism, 23 - vertical working table support, 24 - screw mechanism, 25 latch mechanism, 26 - electrical motor friction brake 
Parameters of the drill bits (Fig. 3):

- drill bit diameter $D_{D}\langle 6.02 ; 11.54 ; 40.13\rangle \mathrm{mm}$,

- main edge contour rake angle $G_{F}\left\langle 0^{\circ} ; 12.52^{\circ} ; 29^{\circ}\right\rangle$,

- main edge contour clearance angle $A_{F}\left\langle 2^{\circ} ; 15.81^{\circ}\right.$; $\left.43^{\circ}\right\rangle$,

- main cutting edge bevel angle in base (frontal) plain $B_{A}\left\langle 0^{\circ} ; 10.83^{\circ} ; 62^{\circ}\right\rangle$,

- side edge height $h_{S E}\langle 0 ; 0.15 ; 0.8\rangle \mathrm{mm}$,

- side surface arc length $l_{S S}\langle 0 ; 4.43 ; 49.4\rangle \mathrm{mm}$,

- height of centering spike $h_{C S}\langle 0 ; 2.27 ; 6.15\rangle \mathrm{mm}$,

- drill bits working part side surface tangential taper $S_{T T}\left\langle 0^{\circ} ; 2.46^{\circ} ; 31^{\circ}\right\rangle$

- drill bit working part side surface axial taper $S_{A T}$ $\left\langle 0 ; 5.11^{\prime} ; 87^{\prime}\right\rangle$ (arc minute),

- lateral stiffness of drill bits mounted in a spindle $E_{L}\langle 8 ; 72.78 ; 1000\rangle N \cdot \mathrm{mm}^{-1}$,

- number of cutting edges $z=2$.

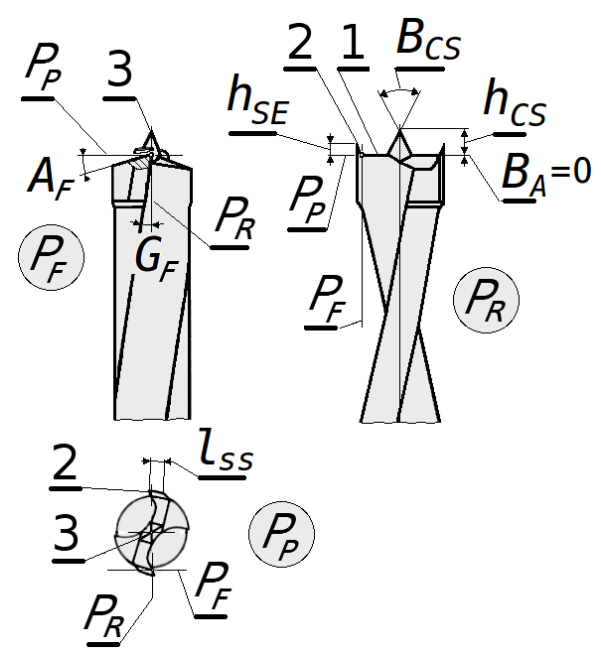

Fig. 3. Stereometrical parameters of the drill bit; 1 - main (face) cutting edge, 2 - side edge, 3 - centering spike, $h_{C S}$ - centering spike height, $h_{S E}$ - side edge height, $l_{S S}$ - side surface arc length, $P_{F}$ - Working plain, $G_{F}$ - rake angle of main cutting edge, $A_{F}-$ clearance of main cutting edge, $B_{A}$ - bevel angle of main cutting edge, $B_{C S}$ - angle of centering spike, $P_{R}$ - tool reference plain, $P_{P}-$ back plain

Parameters of accuracy of the drill bits (Fig. 3)

- radial play of main cutting edge $R_{P}\langle 0.01 \quad 0.02$; $0.07>\mathrm{mm}$,

- radial run out of main cutting edge $R_{R}\langle 0 ; 0.44$; $1.8\rangle \mathrm{mm}$,

- axial run out of main cutting edge $A_{R}\langle 0 ; 0.12$; $0.9\rangle \mathrm{mm}$,

- radial run out of centering spike $R_{R C S}\langle 0 ; 0.08$; $0.55\rangle \mathrm{mm}$,

- axial run out of side edge $A_{R S E}\langle 0 ; 0.04 ; 0.19\rangle \mathrm{mm}$,

- rake angle difference $d G_{F}\left\langle 0^{\circ} ; 0.6^{\circ} ; 1.8^{\circ}\right\rangle$,

- clearance angle differences $d A_{F}\left\langle 0^{\circ} ; 2.68^{\circ} ; 23^{\circ}\right\rangle$
- main cutting edge bevel angle in base (frontal) plain difference $d B_{A}\left\langle 0^{\circ} ; 3.48^{\circ} ; 12^{\circ}\right\rangle$

- side surface arc length difference $d l_{S S}\langle 0 ; 0.24 ; 3\rangle \mathrm{mm}$.

- centering spike maximum asymmetry angle $d B_{C S}\left\langle 0^{\circ} ; 1.87^{\circ} ; 11^{\circ}\right\rangle$.

Physical properties of solid wood specimens:

- Brinell hardness $H B\langle 0.845 ; 1.84 ; 4.025\rangle \mathrm{MPa}$,

- moisture content $12-15 \%$.

Dependent variable was an average hole diameter shift from nominal dimension $d N\langle 0 ; 0.31 ; 1.42\rangle \mathrm{mm}$ and dispersion of holes diameter $D_{H}\langle 0.04 ; 0.46 ; 2.75\rangle \mathrm{mm}$.

Experiments were performed for sharp drill bits.

Diameter $d_{H}$ of 10 shallow, blind holes, drilled for one set of parameters, were measured near the edge in two perpendicular directions, with the use of internal micrometer with accuracy of $0.01 \mathrm{~mm}$, and an average value was taken as a result of the measurement. The hole diameter shift $d N$ was the difference between the average hole diameter $d_{H}$ and the drill bit diameter $D_{D}$. Dispersion of the hole diameter $D_{H}$ was a standard deviation.

In order to eliminate sorption or desorption dimensional changes of machined wood specimen on holes diameter, measurements were performed just after drilling. The diameter of drill bits $D_{D}$ was measured with the use of external micrometer with accuracy of $0.01 \mathrm{~mm}$.

The radial run out $R_{R}$ and axial run out $A_{R}$ and the radial play $R_{P}$ of drill bits mounted in the tool spindle were measured with a dial gauge with accuracy of $0.01 \mathrm{~mm}$, fixed with the use of a universal magnetic stand. The lateral stiffness $E_{L}$ of drill bits mounted in the tool spindle was measured with the use of a dial gauge fixed on a machine table by magnetic stand and hand spring dynamometer.

The other linear and angular parameters of drill bits, like: $h_{C S}, h_{S E}, l_{S S}, S_{A T}, S_{T T}, d G_{F}, B_{A}, d B_{A}, A_{R S E}$ were measured with the use of a tool microscope type BMI, using a prism for drill bits fixing.

The differences $d A_{F}, d G_{F}, d l_{S S}$ and $d B_{A}$ were evaluated for left and right edges.

During the evaluation process of statistical formulas determining quantitative dependencies $d N=f\left(R_{R C S}, S_{A T}\right.$, $A_{R S E}, h_{S E}, n, G_{F}, D_{D}, h_{C S}, A_{R}, R_{R}, E_{L}, R_{P}, A_{F}, d G_{F}$, $\left.S_{T T}, H B, d B_{C S}\right)$ and $D_{H}=f\left(h_{C S}, E_{L}, H B, R_{R}, A_{R}\right.$, $R_{P}, S_{A T}, S_{T T}, R_{R C S}, \mathrm{n}, h_{S E}, G_{F}, d G_{F}, A_{F}, d A_{F}, B_{A}$, $l_{S S}$ ), linear functions, second order multinomial formulas, as well as power type and exponential functions, with and without possible interactions, were analyzed in preliminary calculations. These relations should fit the experimental matrix by the lowest summation of residuals square $S_{K}$, by the lowest $S_{D}$, and by the highest correlation coefficient $\mathrm{R}$ between predicted and observed values. It is also very important to get the proper influence of variables analyzed, especially in the case of an incomplete experimental matrix. Usually the use of a simpler model results in decreasing approximation quality (larger $S_{K}$ and $S_{D}$, and lower $R$ ) and may also re- 
verse the impact of lower importance variables. It should be pointed out that the statistical relationship is valid only for ranges of independent variables chosen in the experimental matrix. For some functions, points lying outside the analyzed range of independent variables, especially evaluated for an incomplete experimental matrix, are usually charged by a significant error.

The most adequate models, according to the made assumptions, appeared to be the exponential equation (1) and (2).

$$
\begin{aligned}
& d N=a_{28} \cdot \exp \left(A_{1}+A_{2}+A_{3}+A_{4}+A_{5}+A_{6}\right) \\
& +a_{29}(0<d N<1.42)(\mathrm{mm}) \\
& A_{1}=a_{1} \cdot d B_{C S}+a_{2} \cdot S_{A T}+a_{3} \cdot A_{R S E}+a_{4} \cdot h_{S E} \\
& A_{2}=a_{5} \cdot n+a_{6} \cdot G_{F}+a_{7} \cdot D_{D}+a_{8} \cdot h_{C S}+a_{9} \cdot A_{R} \\
& A_{3}=a_{10} \cdot R_{R}+a_{11} \cdot E_{L}+a_{12} \cdot R_{P}+a_{14} \cdot A_{F} \\
& A_{4}=a_{16} \cdot d G_{F} \cdot E_{L}+a_{17} \cdot S_{T T}+a_{19} \cdot R_{R} \cdot R_{P} \\
& +a_{20} \cdot H B+a_{13} \cdot E_{L} \cdot h_{C S} \\
& A_{5}=a_{15} \cdot h_{C S} \cdot R_{R C S}+a_{18} \cdot h_{C S} \cdot H B \\
& +a_{21} \cdot R_{R} \cdot E_{L}+a_{22} \cdot R_{R C S} \cdot R_{P}+a_{23} \cdot d B_{C S} \cdot R_{P} \\
& A_{6}=a_{24} \cdot d B_{A} \cdot R_{P}+a_{25} \cdot d B_{C S} \cdot E_{L} \\
& +a_{26} \cdot h_{S E} \cdot R_{P}+a_{27} \cdot A_{R S E} \cdot h_{S E} \\
& D_{H}=b_{34} \cdot \exp \left(B_{1}+B_{2}+B_{3}+B_{4}+B_{5}+B_{6}\right) \\
& +b_{35}\left(0.04<D_{H}<2.75\right)(\mathrm{mm}) \\
& B_{1}=b_{1} \cdot d B_{C S} \cdot E_{L}^{a 28}+b_{2} \cdot S_{A T}+b_{3} \cdot A_{R S E} \cdot E_{L}^{a 29} \\
& +b_{4} \cdot h_{S E} \\
& B_{2}=b_{5} \cdot n+b_{6} \cdot G_{F}+b_{7} \cdot D_{D}+b_{8} \cdot h_{C S} \\
& B_{3}=b_{9} \cdot A_{R}+b_{10} \cdot R_{R}^{b 24} \cdot h_{C S}^{b 30}+b_{11} \cdot E_{L}^{b 31} \\
& +b_{12} \cdot R_{P} \cdot E_{L}^{b 33} \\
& B_{4}=b_{13} \cdot R_{R C S}+b_{14} \cdot A_{F}+b_{15} \cdot d A_{F}+b_{16} \cdot d G_{F} \\
& +b_{17} \cdot S_{T T} \\
& B_{5}=b_{19} \cdot B_{A}+b_{20} \cdot H B \cdot h_{C S}^{b 32}+b_{18} \cdot h_{C S}^{b 22} \cdot E_{L}^{b 23} \\
& B_{6}=b_{21} \cdot h_{C S} \cdot l_{S S}+b_{25} \cdot h_{C S}^{b 26} \cdot R_{P}^{b 27} \text {, }
\end{aligned}
$$

where: $\exp (x)=e^{x}$ and $e=2.7182818$.

Estimators, also called coefficients of regression equation, were evaluated from an incomplete experimental matrix having 145 data points. During the evaluation process of chosen mathematical models, unimportant or low important estimators were eliminatedusing coefficient of relative importance $C_{R I}$, defined by equation (3), by assumption $C_{R I}>0.1$

$$
C_{R I}=\left(S_{K}+S_{K O k}\right) \cdot S_{K}^{-1} \cdot 100(\%)
$$

In equation (3) the new terms are:

- $S_{K 0 k}$-summation of square of residuals, by estimator $a_{k}=0$

- $a_{k}$ - estimator of the number $k$ in empirical formula evaluated.

Summation of square of residuals $S_{K}$, standard deviation of residuals $S_{R}$, correlation coefficient $\mathrm{R}$ and the square of correlation coefficient $R^{2}$, between predicted and observed values were used for characterization of approximation quality [2].

Calculation was performed at Poznań Supercomputing and Networking Center (PCSS) on a SGI Altix 3700 machine, using an optimization program, prepared by the author, based on the least square method. For the defined mathematical formula and initial approximation, this program (Fig. 4) is searching, in an iterative manner, for a solution with minimum summation of square of residuals $S_{K}$. Preferred values of initial estimators can be any small numbers. For linear (LF), polinominal (PNF) as well as trygonometrical functions (TF) it can be just 1.0. For power (PF) and exponential functions (EF) can be respectively 0.1 and 0.001 or smaller, depending on the value of independent variables. Corrected estimators for every loop are determined from a defined range of searches, using gradient and Monte Carlo methods as well as several combinations of them. Construction of the program allows adding new parts to the statistical formula. It is efficient to start calculation from a simple equation and stepwise add new parts. It is also possible to remove parts of the formula due to the lack of importance. In case of reaching the local minimum or out of range instance, calculation needs interference. Depending on the size of an experimental matrix, for LF, PNF and TF cases, a final solution can be found after less than $10^{8}$ iterations. For cases PF and EF, especially for a large number of independent variables, interactions and number of tests, as well as in case of presence of local minimums, the necessary number of iterations can be much higher $\left(10^{13}\right)$.

\section{RESULTS AND DISCUSSION}

Appendix contains a collection of estimators and coefficients of relative importance for equations (1) and (2).

Approximation quality of the fit of the equation (1) can be characterized by the quantifiers: $S_{K}=2.06, R=$ $0.89 ; R^{2}=0.80 ; S_{R}=0.12 \mathrm{~mm}$, and was also illustrated in Fig. 5. The final solution was obtained after the number of iteration of $5.810^{8}$. In formula (1) twelve interactions were found: $-d G_{F} \cdot E_{L},-R_{R} \cdot R_{P}, E_{L} \cdot h_{C S}$, 


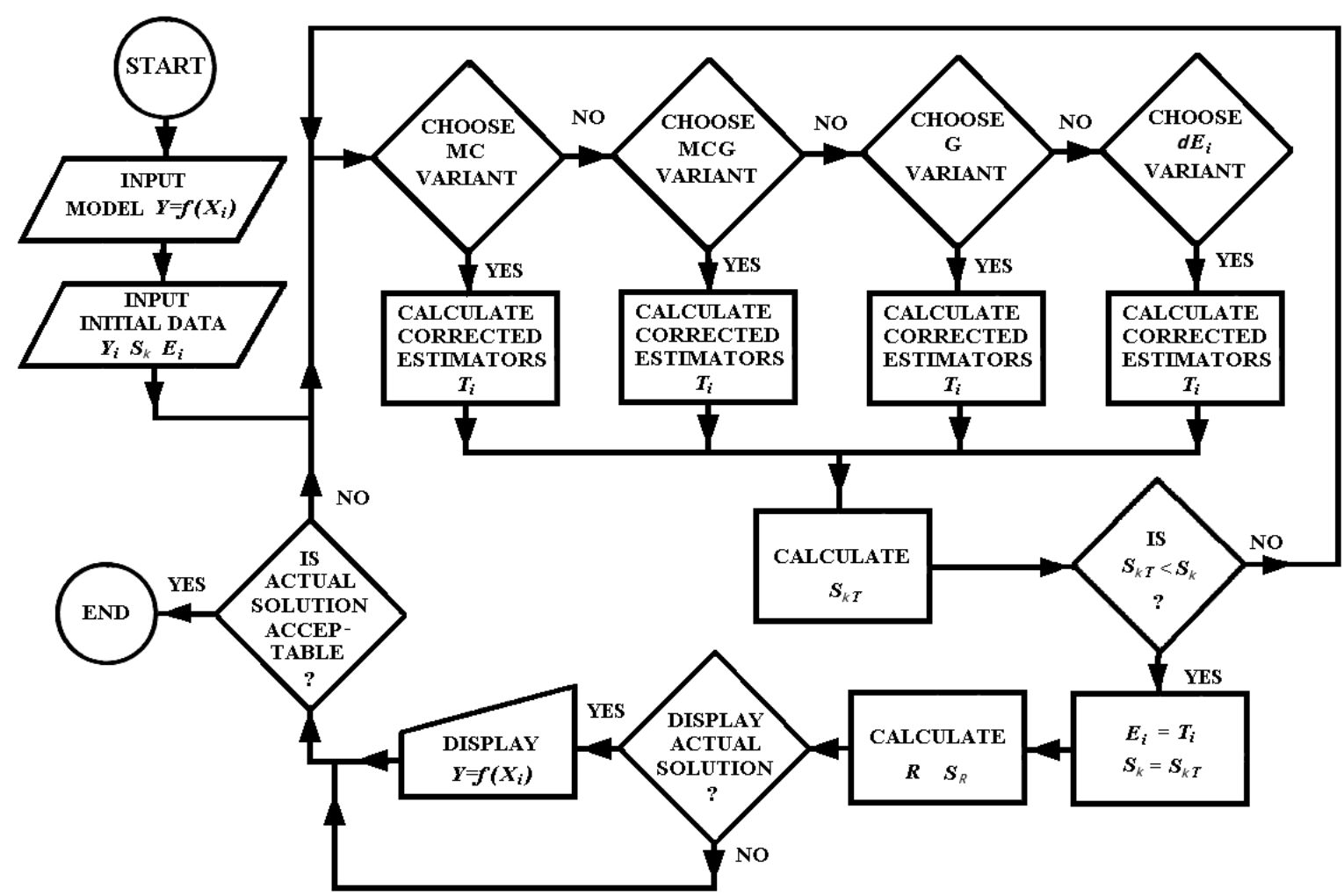

Fig. 4. Flowing chart of the optimization program; variants: MC - Monte Carlo, G - gradient, MCG - combined MC and G, $S_{K}-$ summation of square of residuals, $R$-correlation coefficient, $S_{R}$-standard deviation of residuals

$h_{C S} \cdot R_{R C S},-h_{C S} \cdot H B, R_{R} \cdot E_{L},-h_{C S} \cdot R_{R C S}, d B_{C S} \cdot R_{P}$, $-d B_{A} \cdot R_{P}, d B_{C S} \cdot E_{L},-h_{S E} \cdot R_{P}$ and $A_{R S E} \cdot h_{S E}$. The most involved independent variables in the interactions are: transversal stiffness $E_{L}$, height of the centering spike $h_{C S}$ and - radial play $R_{P}$.

The approximation quality of the fit of the equation (2) can be characterized by quantifiers: $S_{K}=4.83, R=0.92$, $R^{2}=0.84, S_{D}=0.18 \mathrm{~mm}$, and was also illustrated in Fig. 6 . The final result was obtained after the number of iteration of $2.210^{9}$.

In the formula (2) eight interactions can be seen: $d B_{C S}$. $E_{L},-A_{R S E} \cdot E_{L}, R_{R} \cdot h_{C S}, R_{P} \cdot E_{L},-H B \cdot h_{C S}, h_{C S} \cdot E_{L}$, $h_{C S} \cdot l_{S S}, h_{C S} \cdot R_{P}$. The most involved independent variables in the interactions are: transversal stiffness of the drill bit $E_{L}$, height of the centering spike $h_{C S}$, radial run out $R_{R}$ and radial play $R_{P}$.

Figs. 5 and 6 show asymmetric distribution of measuring points of the $d N$ and $D_{H}$. More than $60 \%$ of the $d N$ are lower than $0.25 \mathrm{~mm}$. Differences between the observed and predicted values are low, for several ranges of the $d N$ and $D_{H}$. For some measuring points these differences are much larger. Uncontrolled variation of the $d N$ and $D_{H}$. (Figs. 5 and 6) may have a source in random, unsymmetrical distribution of wood properties in the cutting region. It is also possible an influence of not taken into account independent variables or interactions. The analyzed problem looks very complex. However, most of variation of the $d N$ and $D_{H}$, considered in the past as machining tolerances $[3,5,6]$ was taken into account in the formulas (1) and (2).

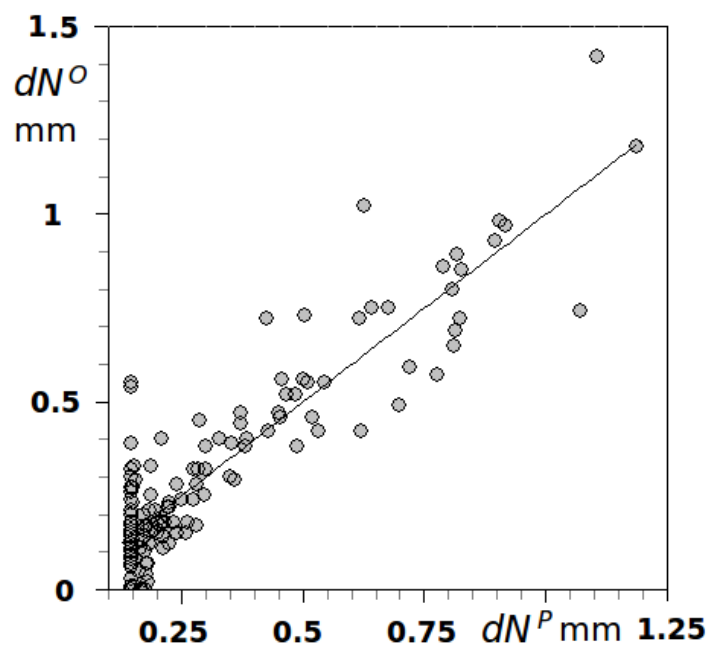

Fig. 5. Plot of observed hole diameter shift $d N^{O}$ against predicted $d N^{P}$ value

Fig. 7 shows that the hole diameter shift $d N$ strongly, non-linearly depends upon the $S_{A T}$ and the $d B_{C S}$. With 
a reduction of the $S_{A T}$ and the $d B_{C S}$ the $d N$ significantly increased. The dependence of the $d N$ from both variables by the $S_{A T}>40^{\prime}$ (where: ' means angle minute) was negligibly small.

Fig. 8 shows the $d N$ dependency from the $A_{R S E}$ and the $h_{S E}$. An increase of the $h_{S E}$, together with an decrease of the $A_{R S E}$, significantly increased the $d N$, by strong increasing tendency.

Fig. 9 reveals slight, positive dependency of the $d N$ from increasing of the $n$ and the $G_{F}$.

Fig. 10 shows hole diameter shift $d N$ strong, non-linear dependency from the $h_{C S}$ and the $D_{D}$. A decrease of the $h_{C S}$ and an increase of the $D_{D}$ increased the average hole diameter shift $d N$. Reduction of the $h_{C S}$ caused significant enlargement of the $d N$, more intensive with increasing of the $D_{D}$.

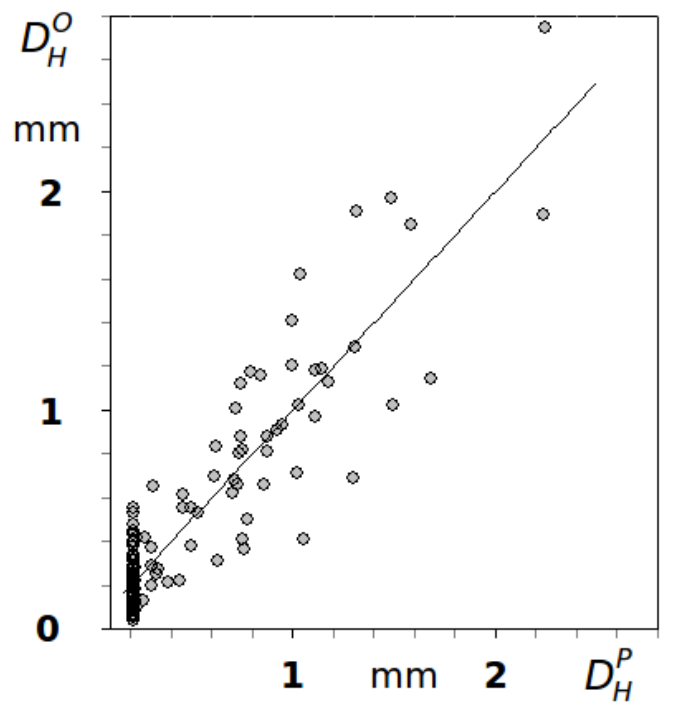

Fig. 6. The plot of observed hole diameter shift $D_{H}{ }^{O}$ against predicted $D_{H}{ }^{P}$ value

Fig. 11 shows influence of the $R_{R}$ and the $A_{R}$ on the $d N$. It can be seen that the $d N$ strongly, nonlinearly increased with an enlargement of the $R_{R}$ for the whole range of variation of the $A_{R}$. However, for low values of the $R_{R}$ the influence of the $A_{R}$ on the $d N$ was negligibly small.

Fig. 12 shows dependency of the $d N$ upon the $E_{L}$ and the $R_{P}$. It can be seen that the $d N$ strongly, nonlinearly increased with an increase of the $E_{L}$, for the whole range of variation of the $R_{P}$. The influence of the $R_{P}$ on the $d N$, for low values of the $E_{L}$ was negligibly small.

Fig. 13 shows dependency of the $d N$ from the $A_{F}$ and $R_{R C S}$. With increasing tendency, an enlargement of the $R_{R C S}$, and decreasing of the $A_{F}$ the $d N$ increased. The influence of the $A_{F}$ was lower and disappeared starting from $R_{R C S}<0.1 \mathrm{~mm}$.

Fig. 14 depicts influence of the $d B_{A}$ and the $S_{T T}$ on the $d N$. An increase of the $d B_{A}$ results in slight decreasing of the $d N$. An increase of the $S_{T T}$ slightly increased the $d N$.
Fig. 15 shows dependence of the $d N$ upon the $H B$ and the $d G_{F}$. An enlargement of the $H B$ decreased the $d N$. The relation $d N=f\left(d G_{F}\right)$ was much smaller. An increase of the $d G_{F}$ results in slight decreasing of the $d N$.

Because of a large number of interactions: $-d G_{F} \cdot E_{L}$, $-R_{R} \cdot R_{P}, E_{L} \cdot h_{C S}, h_{C S} \cdot R_{R C S},-h_{C S} \cdot H B, R_{R} \cdot E_{L}$, $-h_{C S} \cdot R_{R C S}, d B_{C S} \cdot R_{P},-d B_{A} \cdot R_{P}, d B_{C S} \cdot E_{L}$, $-h_{S E} \cdot R_{P}$ and $A_{R S E} \cdot h_{S E}$, dependencies shown in Figs. 7-15 may differ for another set of independent variables.

No correlation between the $d N$ and following independent variables: $d A_{F}, B_{A}, l_{S S}, d l_{S S}$ was found.

Fig. 16 shows that the $D_{H}$ was strongly depended upon the $h_{S E}$. With an increase of the $h_{S E}$ and the $A_{R S E}$ the $D_{H}$ significantly decreased. The side edge seems to have a stabilization effect on the a drill during work.

The hole diameter shift $D_{H}$ was strongly, non-linearly dependent upon the $n$ and the $G_{F}$, which can be seen in Fig. 17. An increase of the $n$ and the $G_{F}$ decreased the average hole diameter dispersion $D_{H}$. With an increase of the $n$ the $D_{H}$ slightly dropped down. Increasing accuracy of the drilling process with increase of the $n$ and $G_{F}$ can be associated with shortening of cutting (larger $\mathrm{n}$ ) and lowering cutting forces (lower $G_{F}$ ).

The hole diameter shift $D_{H}$ was strongly, non-linearly dependent upon the $h_{C S}$ and the $D_{D}$, which can be seen in Fig. 18. An increase of the $h_{C S}$ and the $D_{D}$ increased the dispersion of hole diameter $D_{H}$. With an decrease of the $h_{C S}$ the $D_{H}$ slightly dropped down. This relation was more intensive for large $D_{D}$ and $h_{C S}$. For low $h_{C S}$ the relation $D_{H}=f\left(D_{D}\right)$ was negligibly small.

The hole diameter shift $D_{H}$ was strongly, non-linearly depend upon the $R_{R}$, which can be seen in Fig. 19. An increase of the $R_{R}$ increased the dispersion of hole diameter $D_{H}$. This influence of the relation $A_{R}$ was negligibly small for low values of the $R_{R}$.

Fig. 20 shows dependency of the $R_{P}$ upon the $E_{L}$. It can be seen that the $D_{H}$ strongly, nonlinearly decreased with an increase of the $R_{P}$, especially for larger values of the $E_{L}$. For low $E_{L}$ the relation $D_{H}=f\left(R_{P}\right)$ was negligibly small.

Fig. 21 shows dependency of the $D_{H}$ upon the $A_{F}$ and the $R_{R C S}$. It can be seen that the $D_{H}$ nonlinearly decreased with an increase of the $A_{F}$. The influence of the $R_{R C S}$ on the $D_{h}$ was very small.

Fig. 22 shows the $D_{H}$ dependency on the $d G_{F}$ and the $d A_{F}$. With an increase of the $d G_{F}$ the $D_{H}$ decreased. The influence of the $d A_{F}$ was opposite and lower, especially for the highest $d G_{F}$.

Fig. 23 depicts the influence of the $S_{T T}$ and the $B_{A}$ on the $D_{H}$. An increase of the $S_{T T}$ and of the $B_{A}$ results in slightly increasing of the $D_{H}$.

Fig. 24 shows the influence of the $H B$ and the $h_{C S}$ on the $D_{H}$. An increase of the $h_{C S}$ slightly decreased the $D_{H}$ for large values of the $H B$. For small values of the $H B$, increasing value of the $h_{C S}$ rapidly increasing of the $D_{H}$ can be seen. For high $h_{C S}$ and the $H B$ the relation $D_{H}=f\left(h_{C S}, H B\right)$ was negligibly small. 


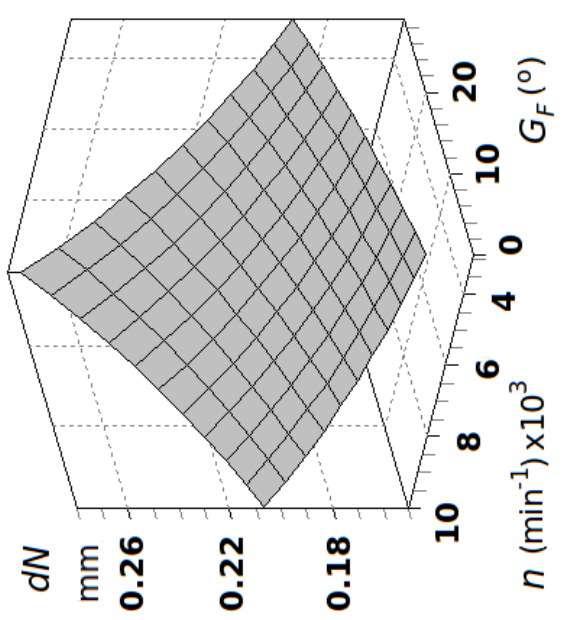

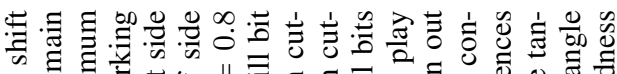

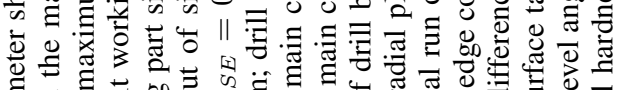

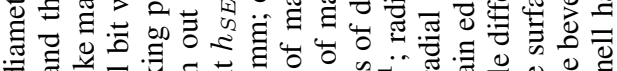

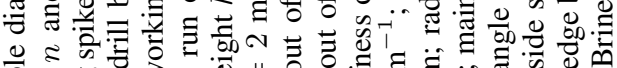

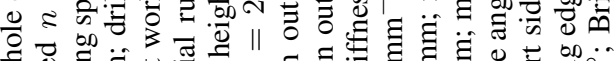

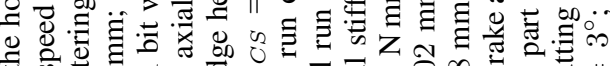

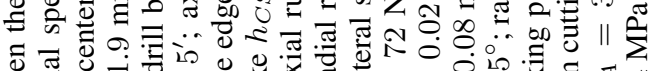

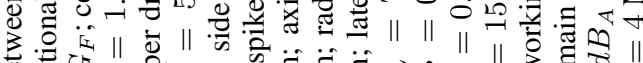

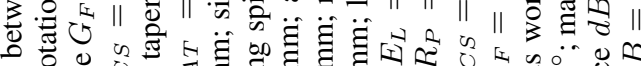

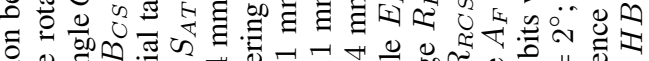

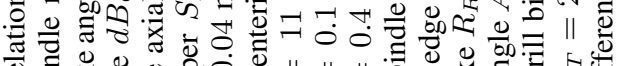

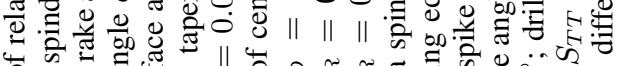
के की

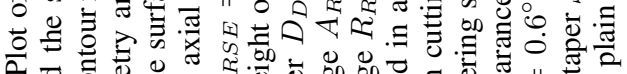

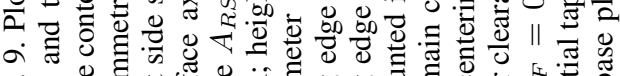

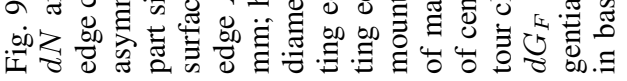

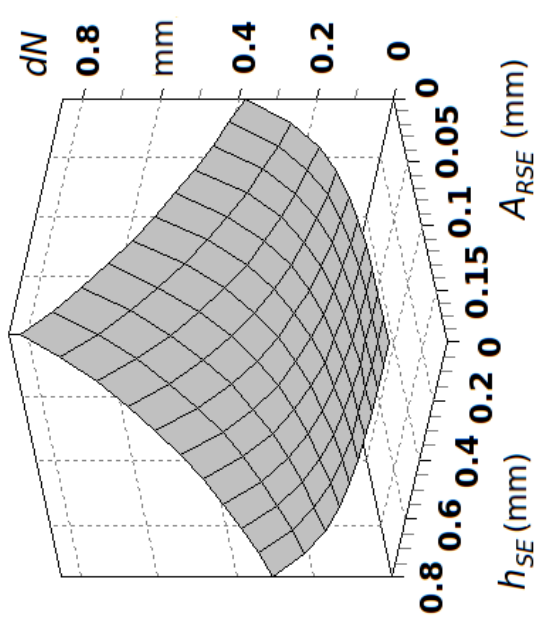

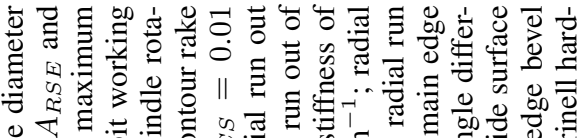
ㄴ.

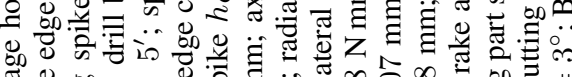
$\varpi_{0} \&$ on

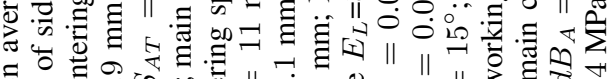

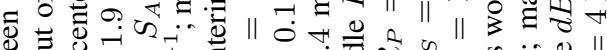
ठํ. 造等

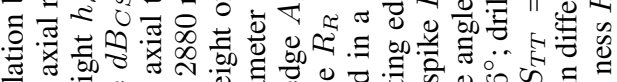

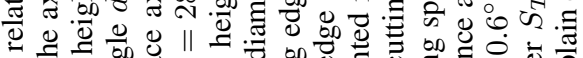

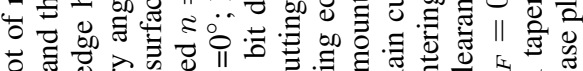

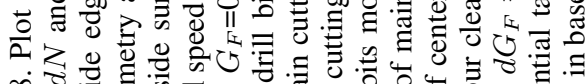

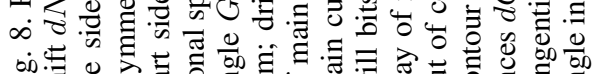

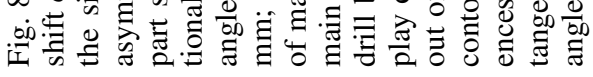

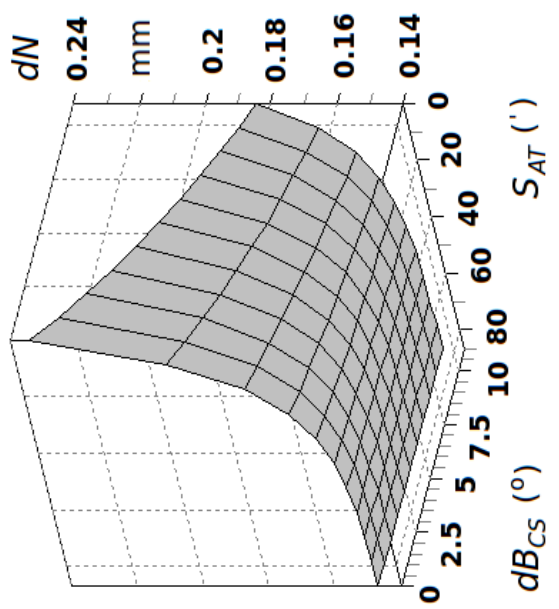

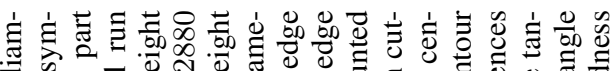
哥

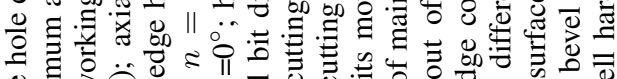

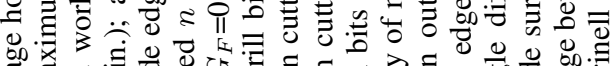

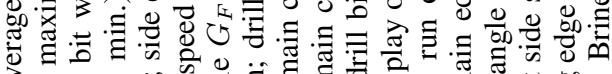

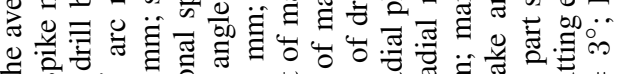

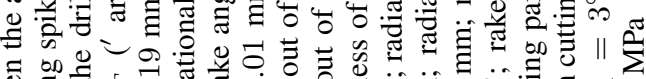

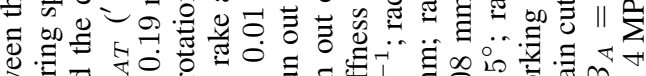

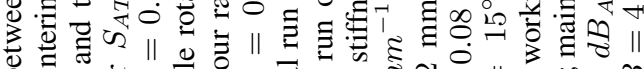

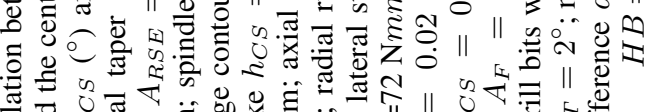

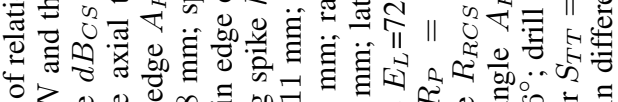

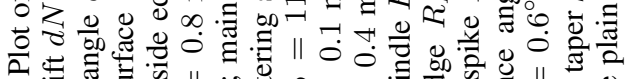

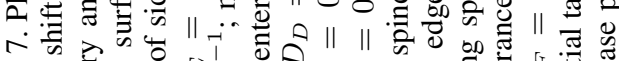

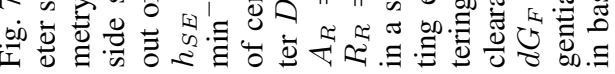




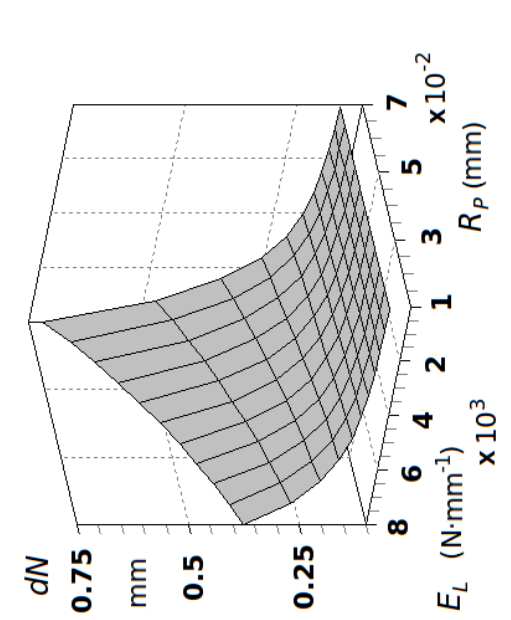

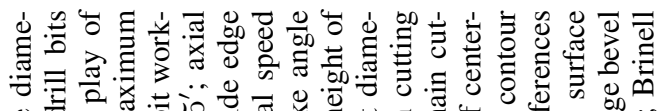

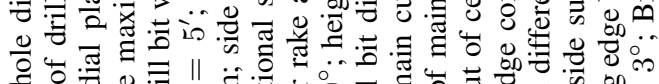

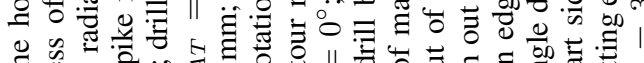

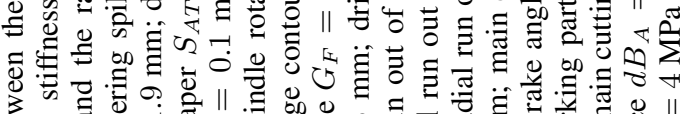

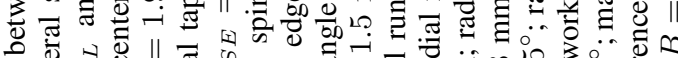

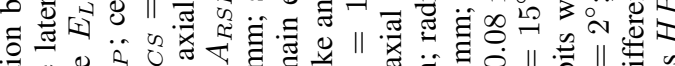

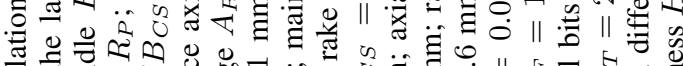

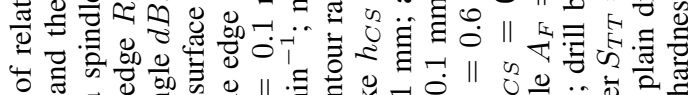

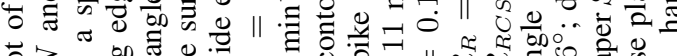

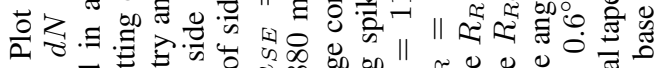
¿

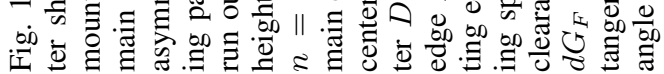

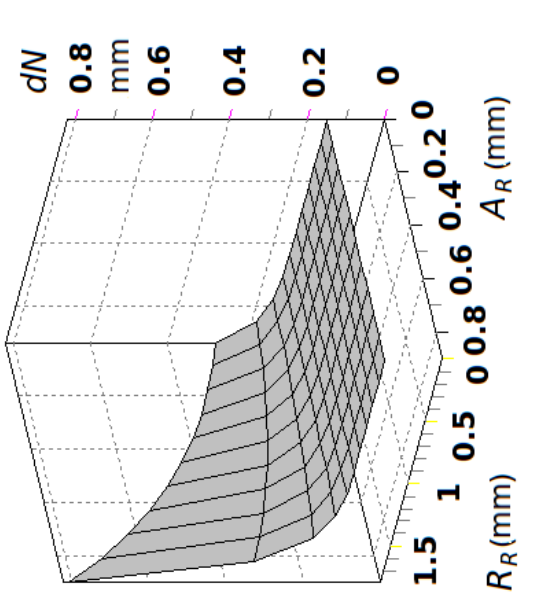

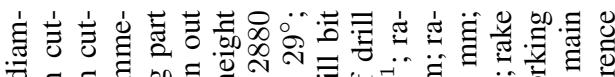

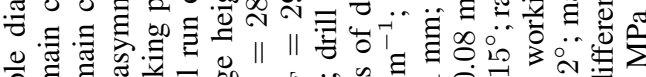

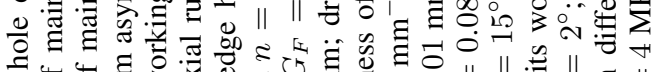

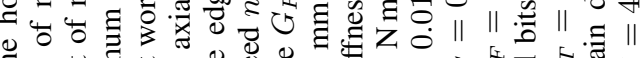

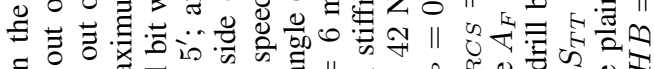

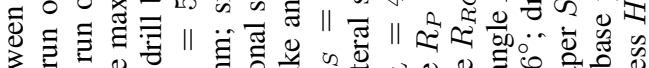

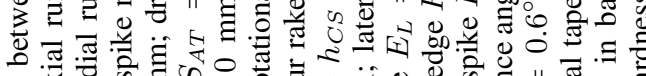

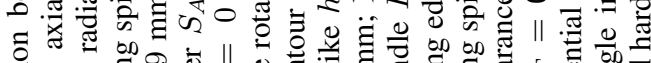
.

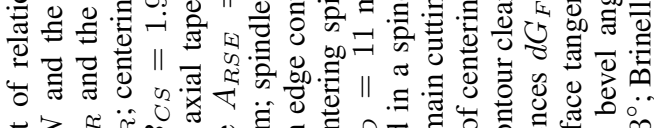

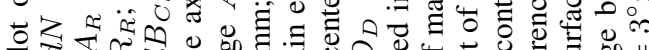

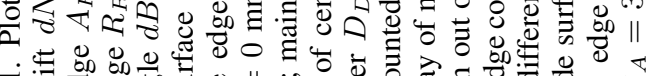

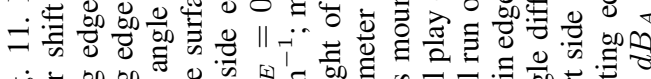

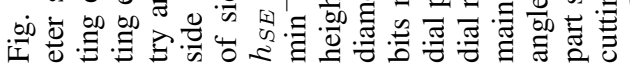

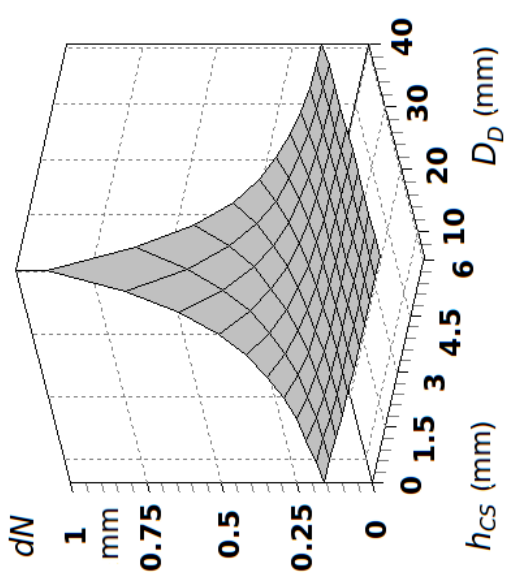

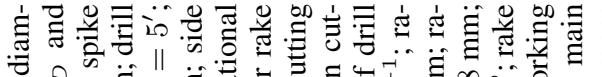

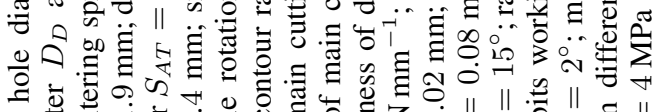

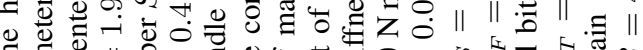
要

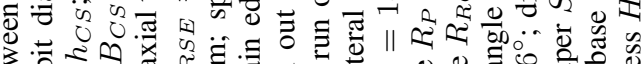

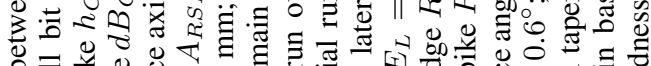

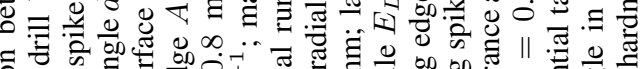

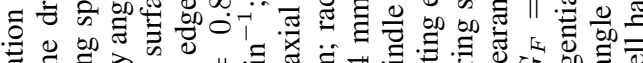

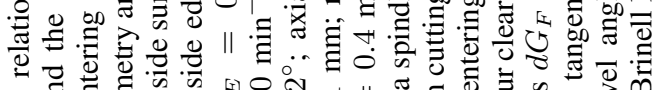

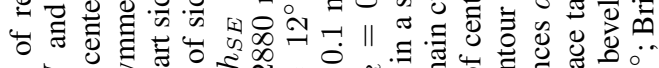

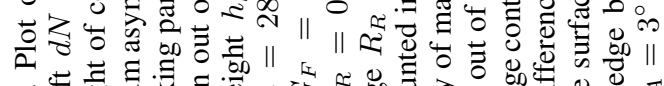

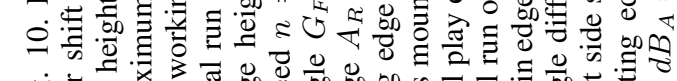

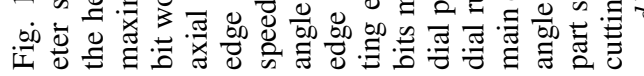




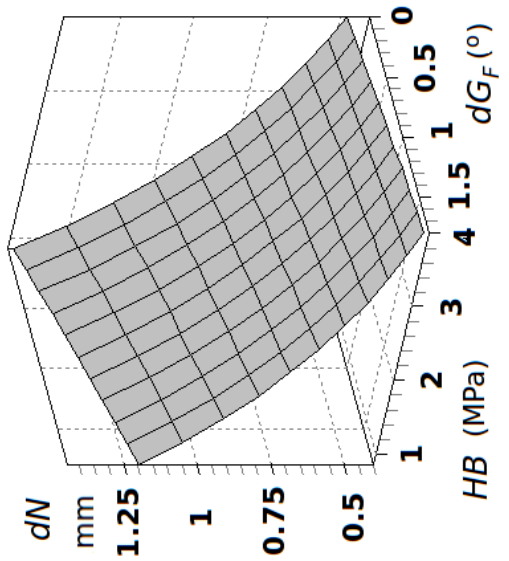

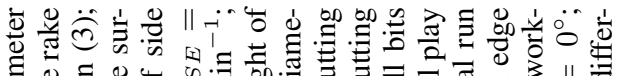

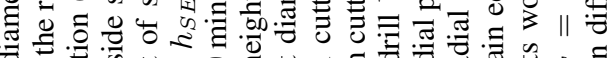

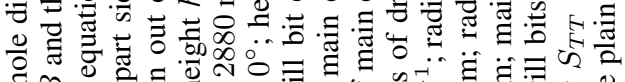

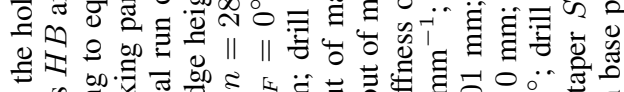

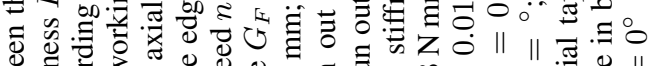

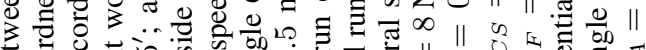

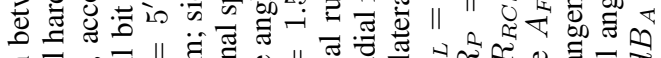

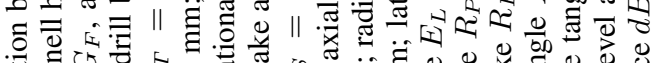

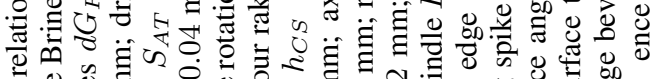

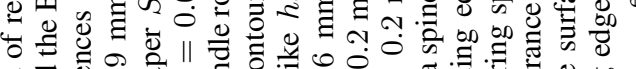

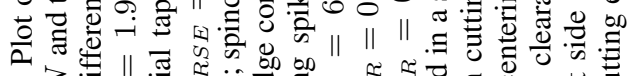

的方守

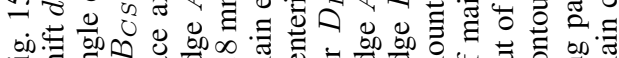

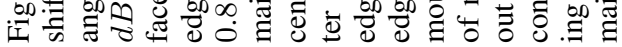

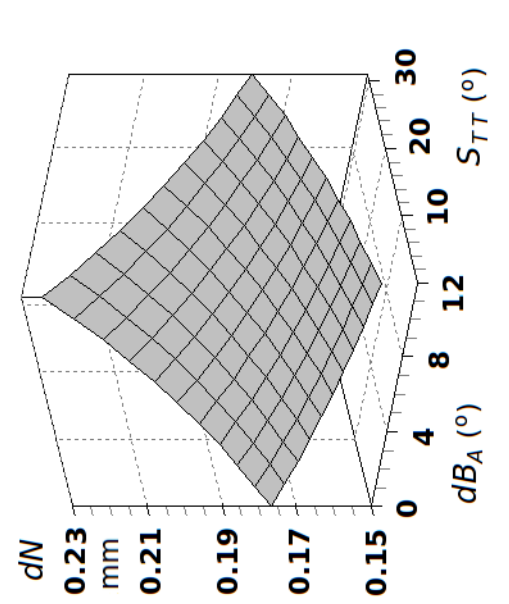

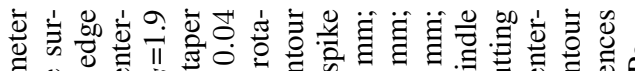

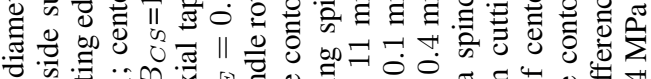

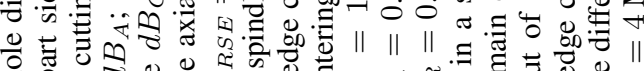

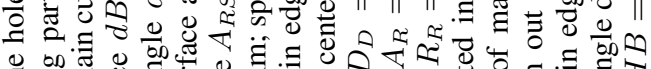

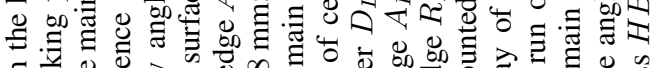
उ

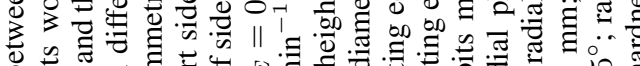

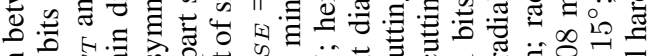

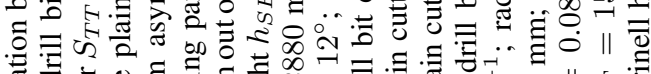

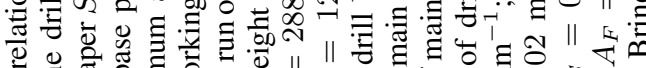

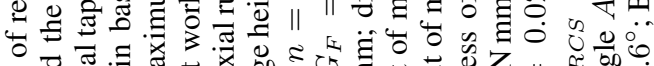

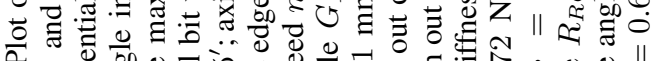

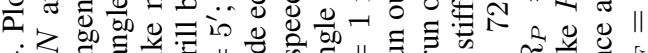

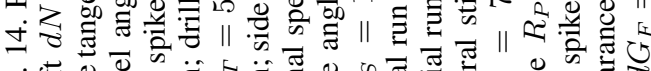

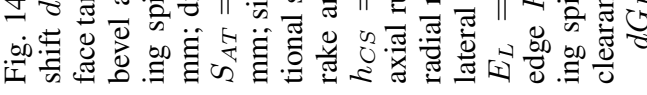

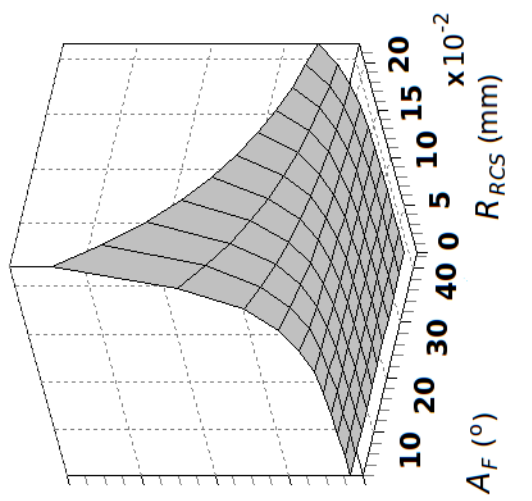

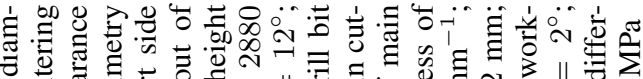

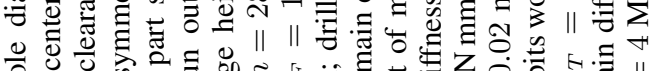

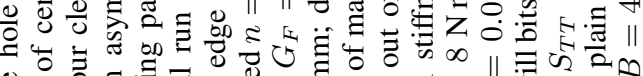

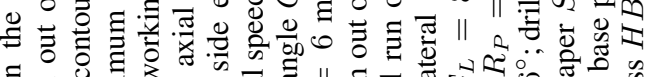

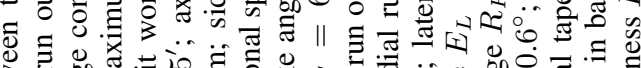

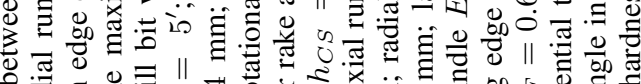

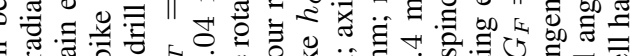

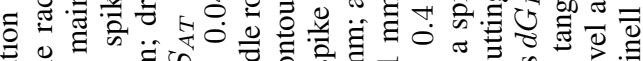

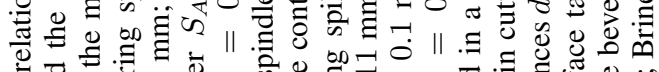

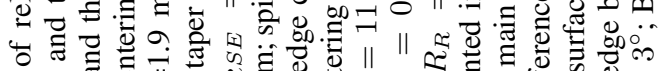
녕 o

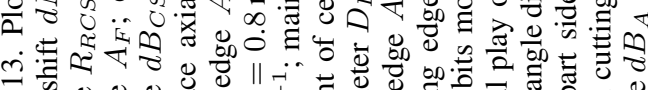

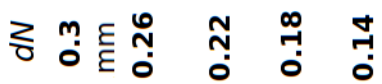

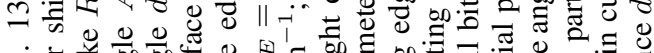

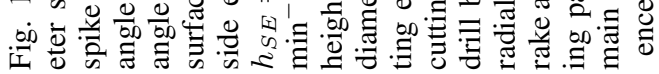




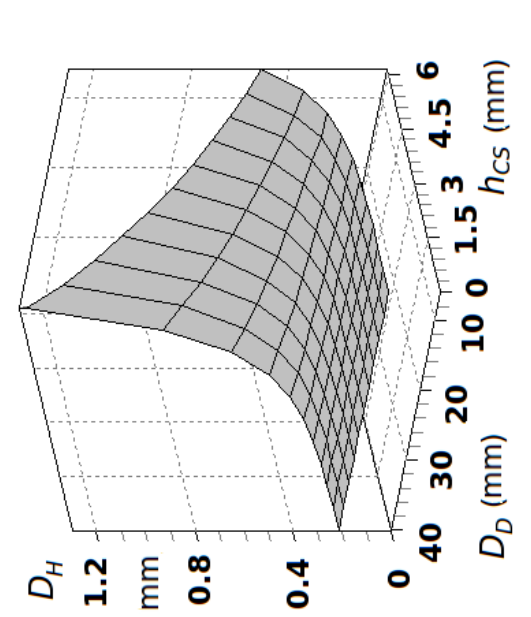

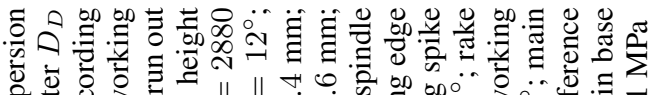

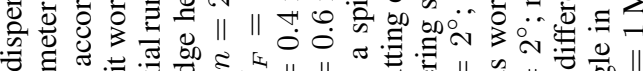

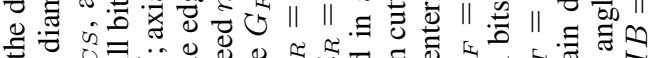

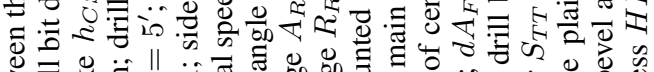

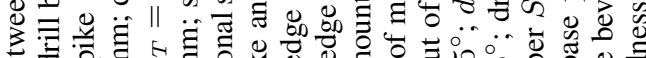

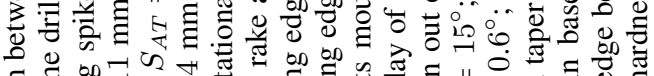

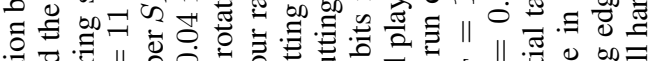

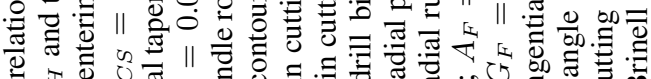

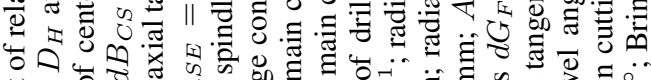

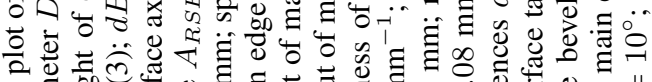

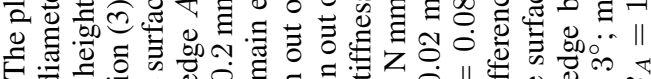

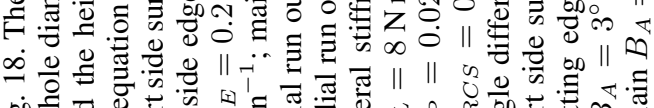

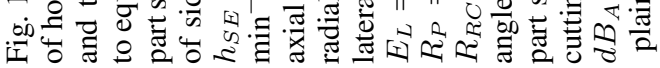

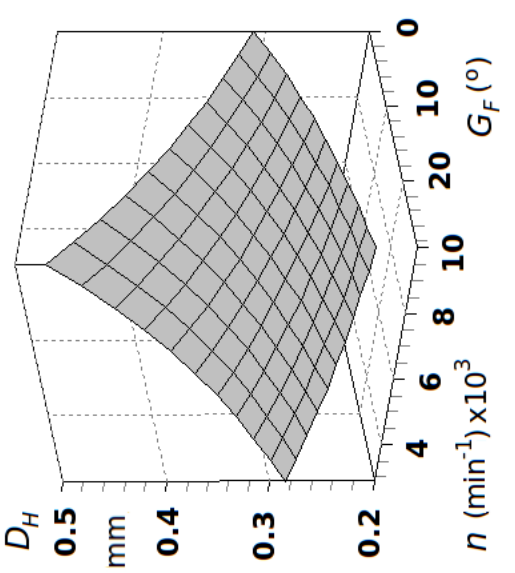

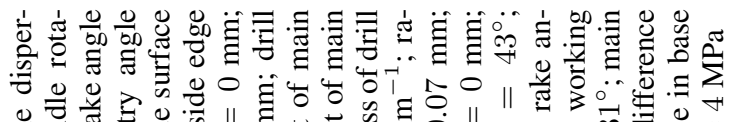

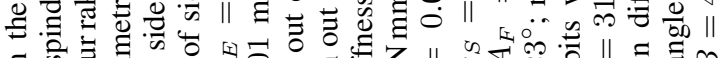
б के

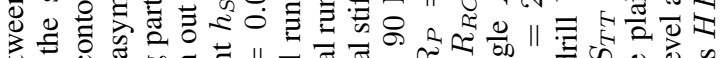

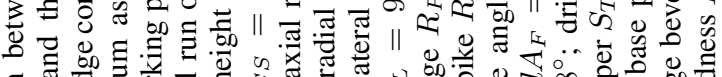

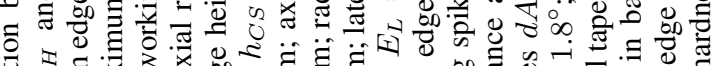

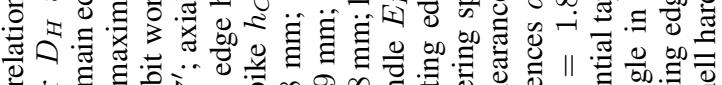

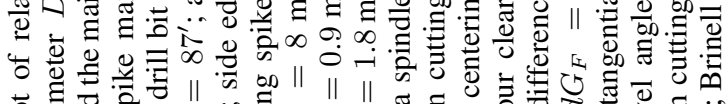

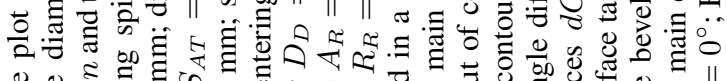

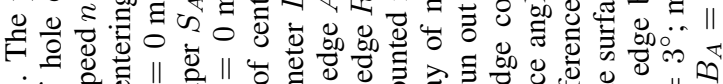

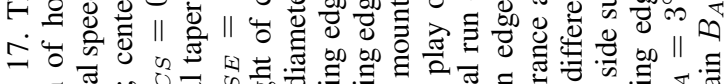

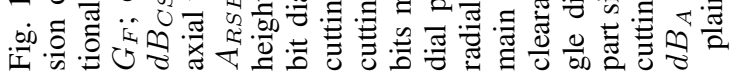

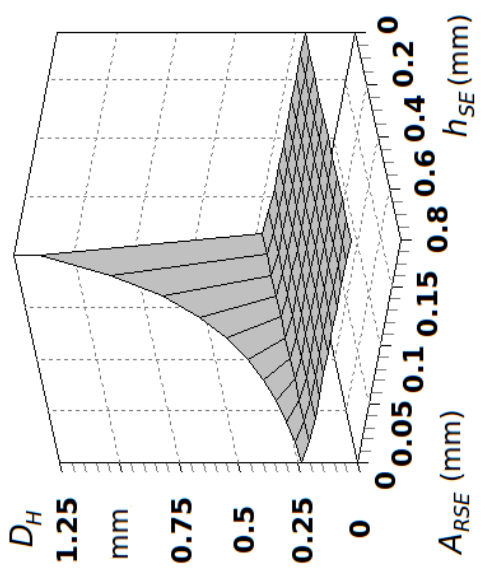

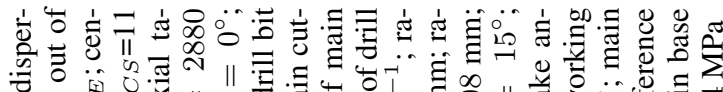

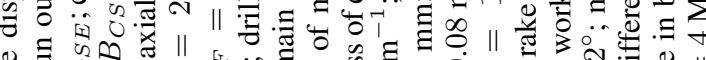

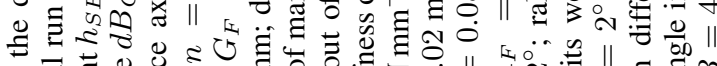

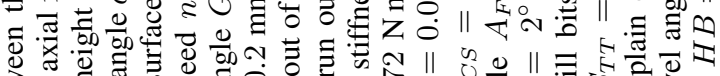

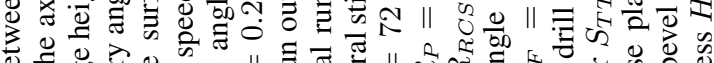

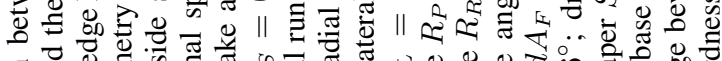

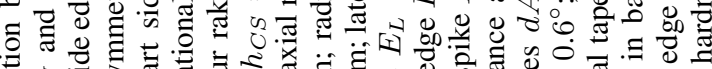

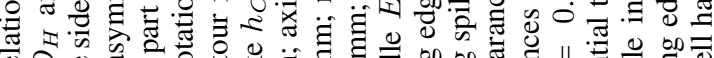
Q

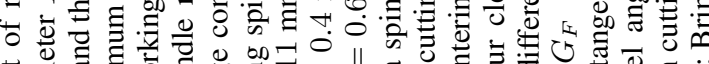
을 不 2.च W

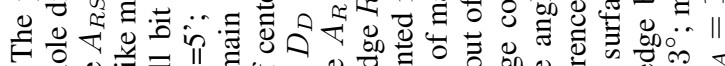

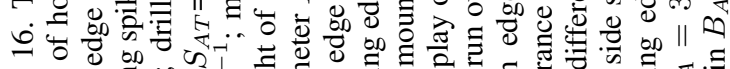

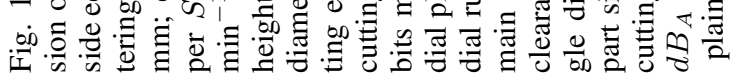




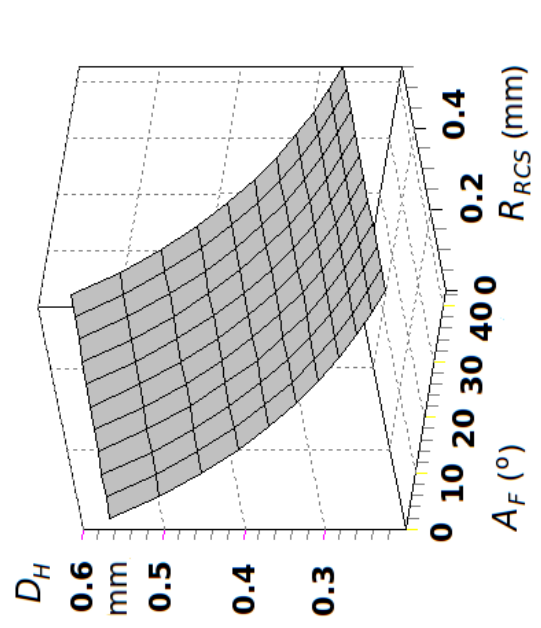

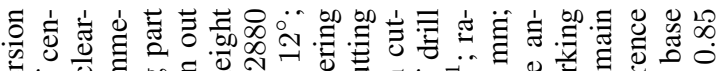

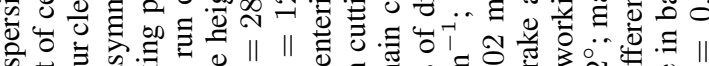

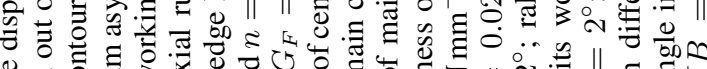

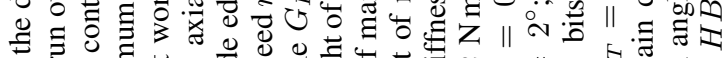

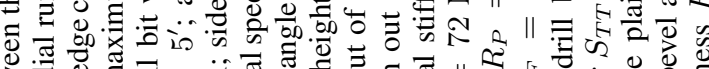

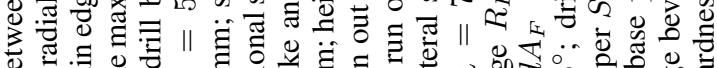

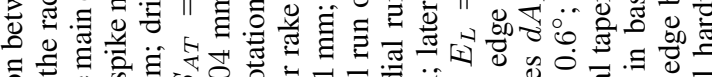
等

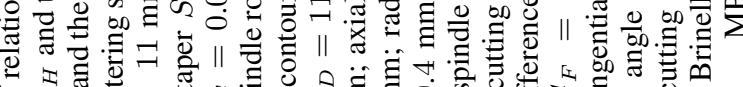

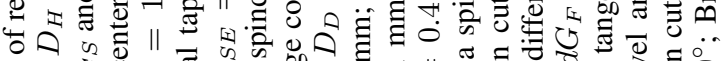
흔

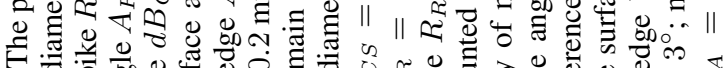
ते 0

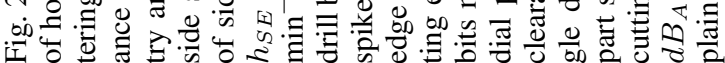

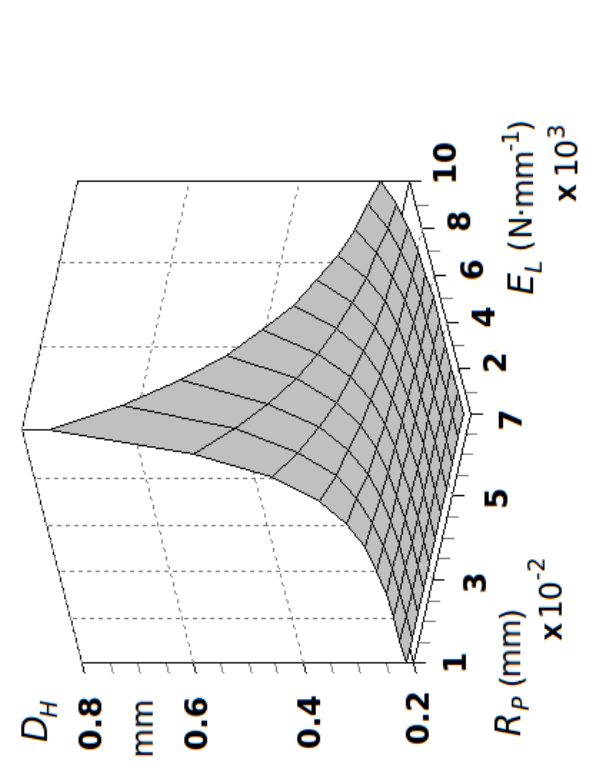

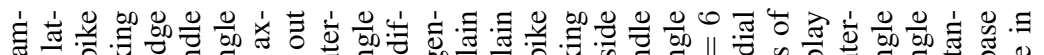

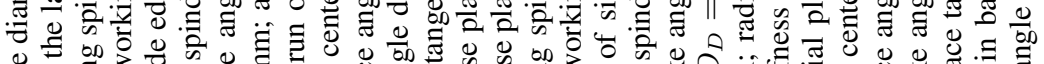

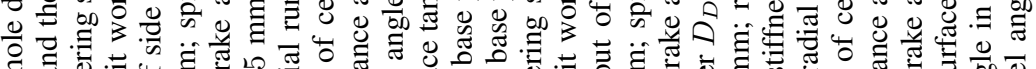

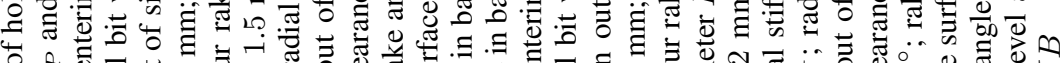

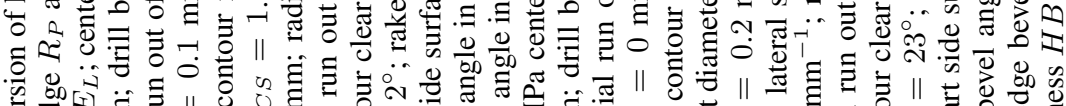

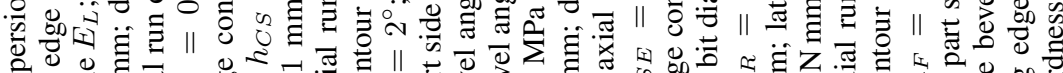

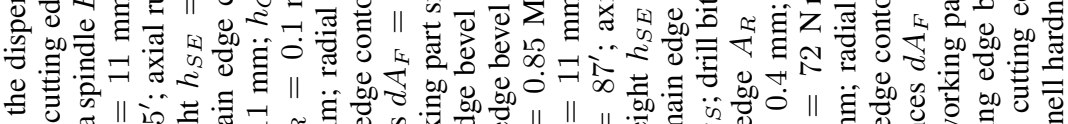

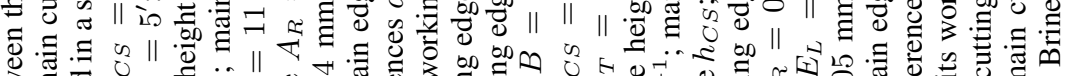

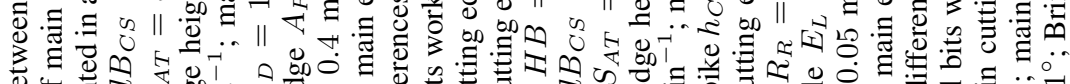

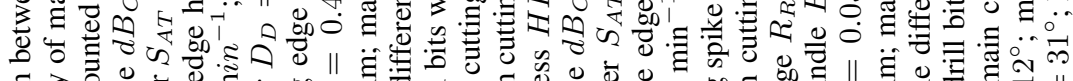

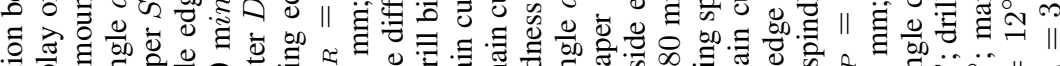

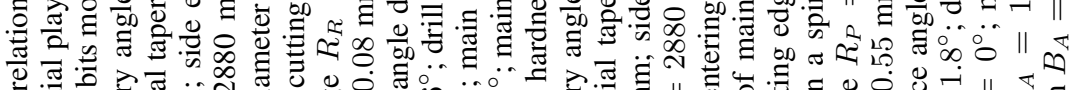

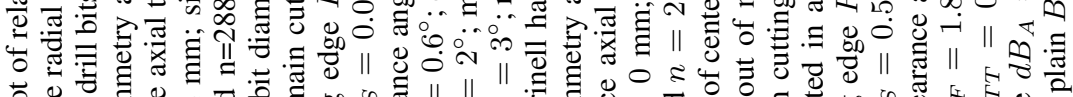

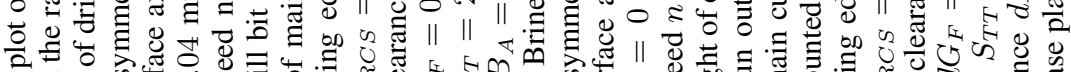

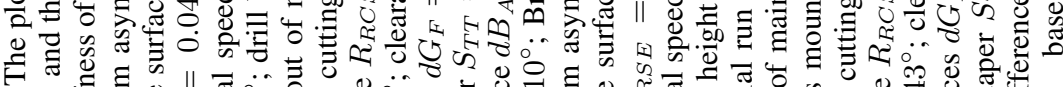

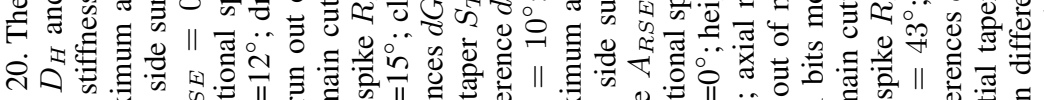

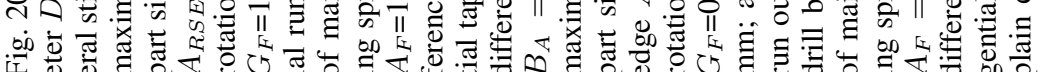

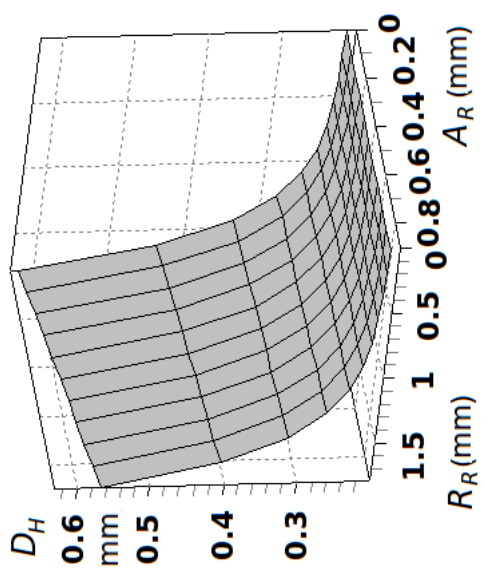

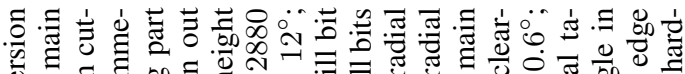

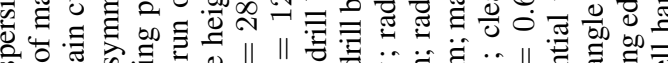

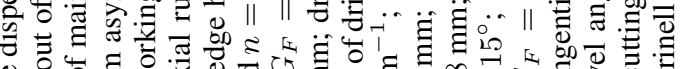
巳

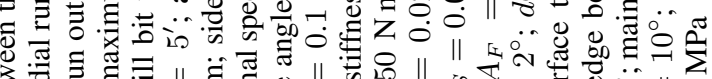

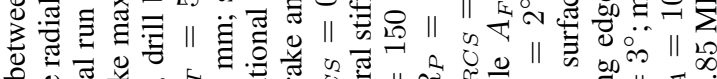

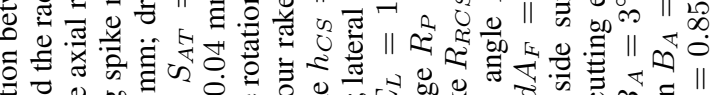

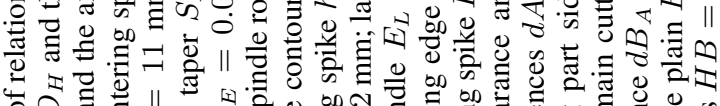

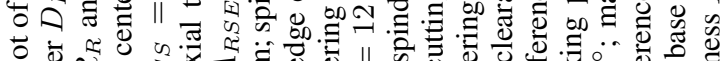

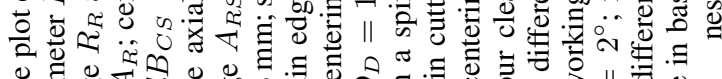

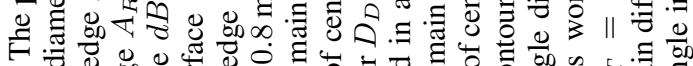

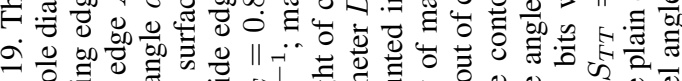

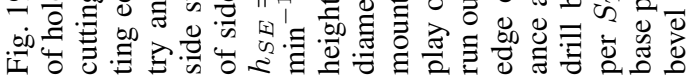




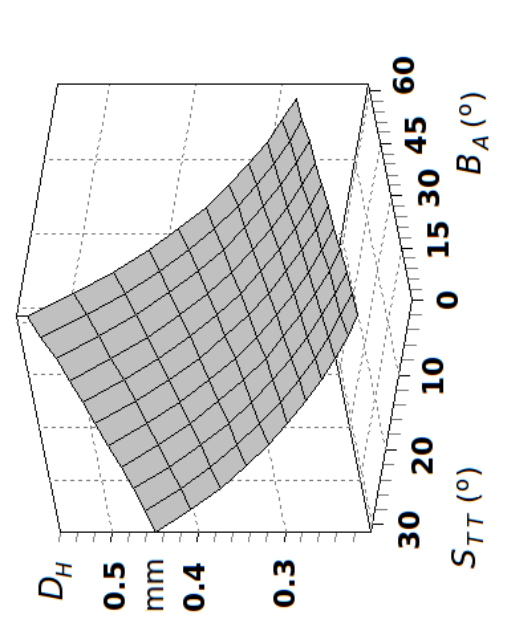

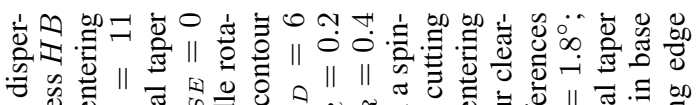

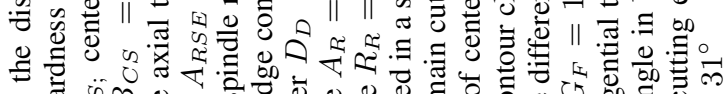
于

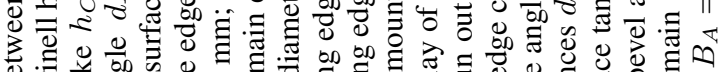

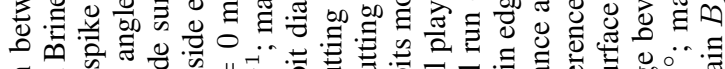

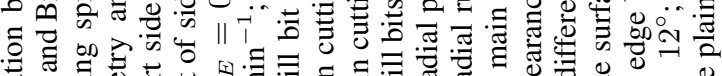

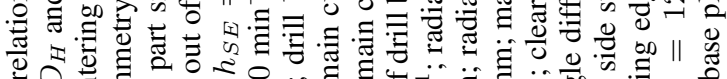

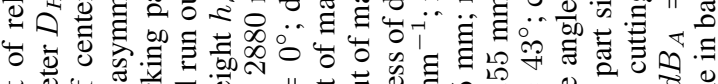
흠

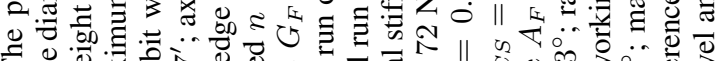

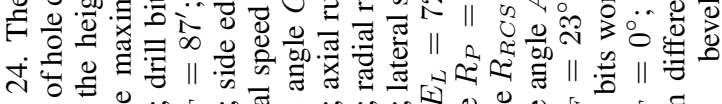

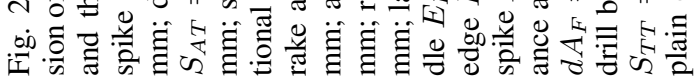

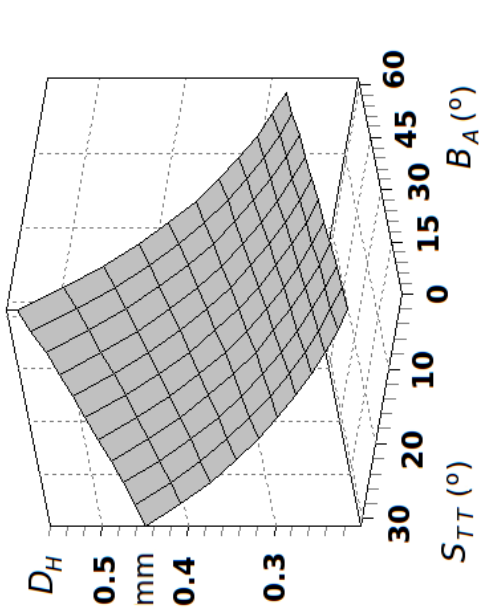

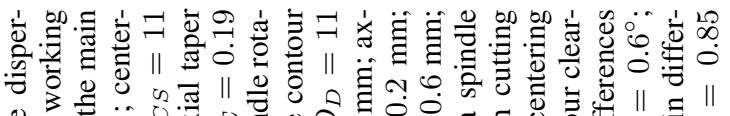

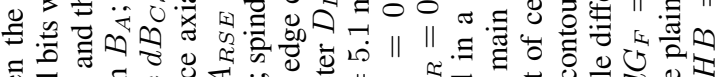

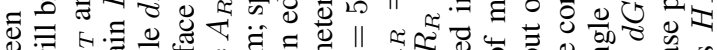

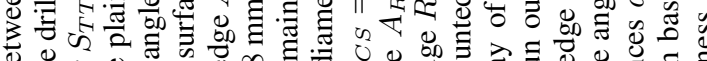

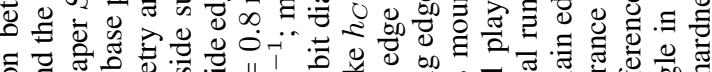

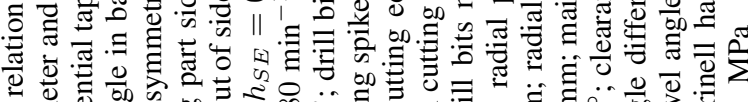

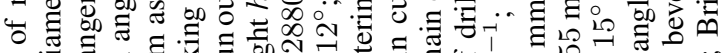

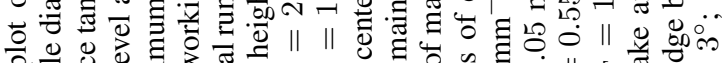

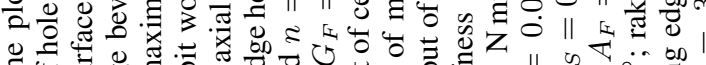

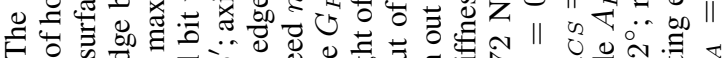

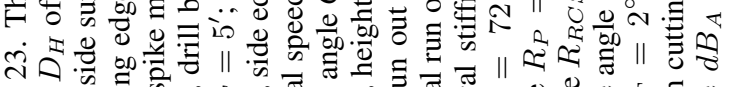

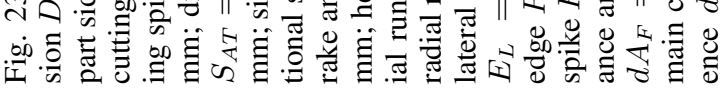

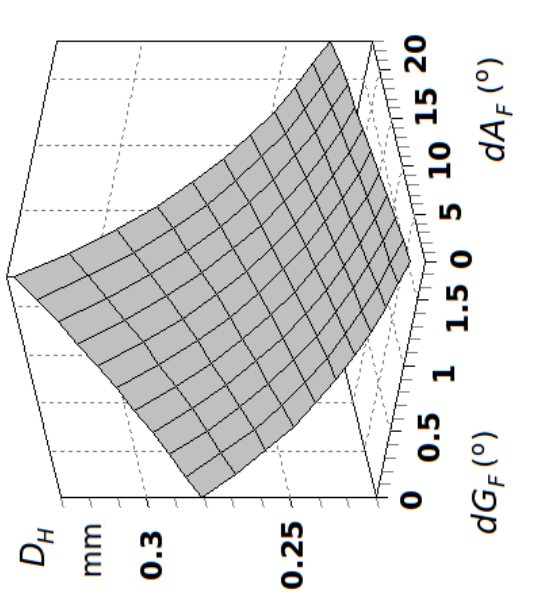

它

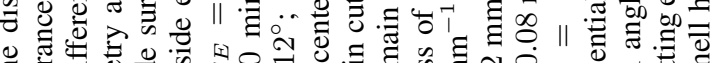

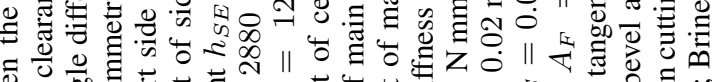

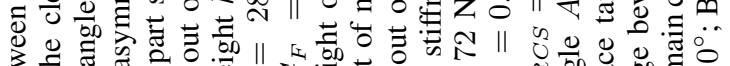

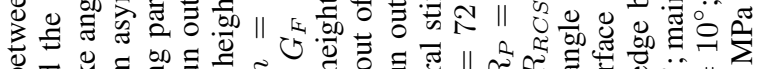

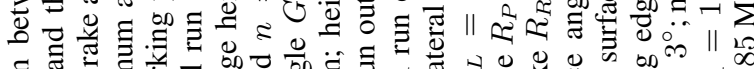

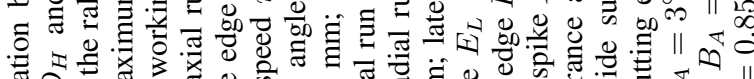

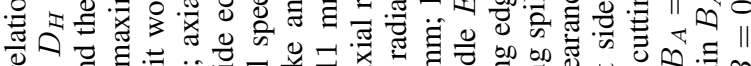

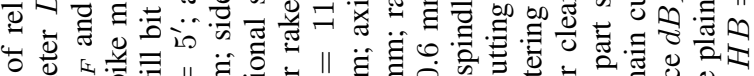

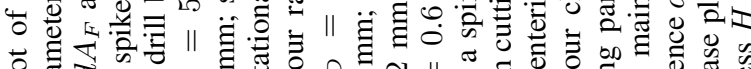

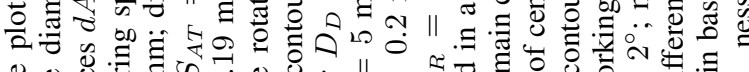
记

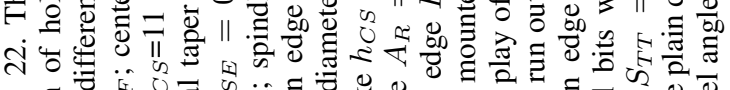

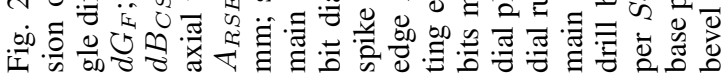


Because of interactions: $d B_{C S} \cdot E_{L},-A_{R S E} \cdot E_{L}$, $R_{R} \cdot h_{C S}, R_{P} \cdot E_{L},-H B \cdot h_{C S}, h_{C S} \cdot E_{L}, h_{C S} \cdot l_{S S}$, $h_{C S} \cdot R_{P}$, the dependency of the $D_{H}$ upon analyzed variables may differ from those presented in Figs. from 16 to 24 for another set of independent variables.

No correlation between the $D_{H}$ and following independent variables: $d B_{A}, B_{A}, d l_{S S}$ was found.

Acceptable hole diameter dispersion $D_{H}$ can be obtained by low value of: $R_{R}, A_{R}$ and high values of $A_{R S E}, h_{S E}, n$, $G_{F}$. In case of high values of the $H B$, despite of some drill bit inaccuracies, acceptable $D_{H}$ can be obtained by large values of the $h_{C S}$. This observation is not valid for low values of the $H B$ (Fig. 24). It should be noted that formulas (1) and (2) are not valid for combinations of independent variables, not present in the examined incomplete experimental matrix, and, giving values $(0>d N>1.48) \mathrm{mm}$ and $\left(0.04>D_{H}>2.75\right) \mathrm{mm}$.

The performed experiments show that it is possible to control, up to a certain level (standard deviation of residuals $S_{R}$ ), the drilling holes accuracy what condition is to identify all machining parameters.

\section{CONCLUSIONS}

Experiments and analysis of the performed results allow stating that:

1. When drilling solid wood of the Scotch pine, the dependency of the shift of hole diameter $d N$ from several machining parameters $d N=f\left(R_{R C S}, S_{A T}\right.$, $A_{R S E}, h_{S E}, \mathrm{n}, G_{F}, D_{D}, h_{C S}, A_{R}, R_{R}, E_{L}, R_{P}$, $\left.A_{F}, d G_{F}, S_{T T}, H B, d B_{C S}\right)$, can be described by formula (2), by: $S_{K}=2.06, R=0.89 ; R^{2}=0.80$; $S_{D}=0.12 \mathrm{~mm}$.

2. The height of centering spike $h_{C S}$, lateral stiffness of drill bits mounted in a spindle $E_{L}$ and radial run out of main cutting edge $R_{R}$, independent variables had the largest influence on the shift of hole diameter $d N$.

3. The largest values of the shift of hole diameter $d N$ was observed by a minimum value of the height of centering spike $h_{C S}$.

4. The largest values of the shift of hole diameter $d N$ was observed by a maximum value of the lateral stiffness of drill bits mounted in a spindle $E_{L}$ and radial run out of main cutting edge $R_{R}$.

5. A decrease of the shift of hole diameter $d N$ was observed by an increase of the: height of centering spike $h_{C S}$, Brinell hardness $H B$, drill bits working part side surface tangential taper $S_{T T}$ and an decrease of the: lateral stiffness of drill bits mounted in a spindle $E_{L}$, drill bit diameter $D_{D}$, radial run out of main cutting edge $R_{R}$, as well as axial run out of main cutting edge $R_{R}$.

6. When drilling solid wood of Scotch pine, the dependency of the dispersion of hole diameter $D_{H}$ from several machining parameters $D_{H}=f\left(R_{R C S}, E_{L}\right.$, $S_{A T}, A_{R S E}, h_{S E}, \mathrm{n}, G_{F}, D_{D}, h_{C S}, A_{R}, R_{R}, R_{P}$, $\left.A_{F}, d A_{F}, d G_{F}, S_{T T}, B_{A}, H B\right)$, can be described by formula (2), by: $S_{K}=2.06, R=0.89 ; R^{2}=0.80$; $S_{D}=0.12 \mathrm{~mm}$.

7. The height of centering spike $h_{C S}$, the lateral stiffness of drill bits mounted in a spindle $E_{L}$ and the radial run out of main cutting edge $R_{R}$ independent variables had the largest influence on the dispersion of hole diameter $D_{H}$.

8. The largest values of the dispersion of hole diameter $D_{H}$ was observed by a minimum value of the height of centering spike $h_{C S}$.

9. The largest values of the dispersion of hole diameter $D_{H}$ was observed by a maximum value of the lateral stiffness of drill bits mounted in a spindle $E_{L}$ and the radial run out of main cutting edge $R_{R}$.

10. A decrease of the dispersion of hole diameter $D_{H}$ was observed by a decrease of the following independent variables: height of centering spike $h_{C S}$, by $H B<1.3$, lateral stiffness of drill bits mounted in a spindle $E_{L}$, radial run out of main cutting edge $R_{R}$, drill bit diameter $D_{D}$, drill bits working part side surface tangential taper $S_{T T}$, main cutting edge bevel angle in base (frontal) plain $B_{A}$, main edge contour rake angle $G_{F}$, clearance angle differences $d A_{F}$.

\section{Acknowledgements}

The author is grateful for the support of the Poznan Supercomputing and Networking Center (PCSS) calculation grant.

\section{References}

[1] K. Banshoya, Y. Kitani, Differences in burr formation in machine through-hole boring of woo-based materials by boring tools, Proc. of $16^{\text {th }}$ International Wood Machining Seminar, Matsue, Japan: 515-523, 2003.

[2] N.R. Draper, H. Smith, Analiza regresji stosowana (in Polish), PWN, Warszawa, 1973.

[3] W. Marzymski, Badanie dokładności maszynowej obróbki skrawaniem drewna $i$ wynikajace przestanki do ustalenia jednostki tolerancji, Zeszyty Naukowe Politechniki Szczecińskiej 83 (1966).

[4] T. Ohuchi, N. Suzuki, W. Murase, Axial deviation of hole in deep machine-boring of wood. Proc. of $16^{\text {th }}$ International Wood Machining Seminar, Matsue, Japan: 524-531, 2003.

[5] B. Porankiewicz, Problem tolerancji i pasowan dla przemystu drzewnego (in Polish), Rocz. AR Poznań, Prace habilitacyjne 183, 70 (1989).

[6] TGL 24421 (1972) Masstoleranzen und Passungen für die Möbelindustrie, p. 1-35, 1972. 


\section{Appendix}

Following estimators for equation (1), describing the dependence $d N=f\left(R_{R C S}, S_{A T}, A_{R S E}, h_{S E}, n, G_{F}, D_{D}, h_{C S}\right.$, $\left.A_{R}, R_{R}, E_{L}, R_{P}, A_{F}, d G_{F}, S_{T T}, H B, d B_{C S}\right)$ were evaluated:

$$
\begin{aligned}
& \text { - } a_{1}=-0.80121, \\
& \text { - } a_{2}=-0.06955, \\
& \text { - } a_{3}=-31.54445, \\
& \text { - } a_{4}=5.04548, \\
& \text { - } a_{5}=1.4082610^{-4}, \\
& \text { - } a_{6}=0.02625, \\
& \text { - } a_{7}=0.11193, \\
& \text { - } a_{8}=-1.00176, \\
& \text { - } a_{9}=1.80529, \\
& \text { - } a_{10}=0.41386, \\
& \text { - } a_{11}=-0.0967, \\
& \text { - } a_{12}=28.88261, \\
& \text { - } a_{13}=3.7948810^{-3}, \\
& \text { - } a_{14}=-0.05196, \\
& \text { - } a_{15}=5.66612, \\
& \text { - } a_{16}=-0.01345, \\
& \text { - } a_{17}=0.03073, \\
& \text { - } a_{18}=-0.18505, \\
& \text { - } a_{19}=-26.6443, \\
& \text { - } a_{20}=-0.15406, \\
& \text { - } a_{21}=0.1583, \\
& \text { - } a_{22}=-139.6572, \\
& \text { - } a_{23}=15.3268, \\
& \text { - } a_{24}=-3.44529, \\
& \text { - } a_{25}=5.8214510^{-3}, \\
& \text { - } a_{26}=-53.33068, \\
& \text { - } a_{27}=30.0126, \\
& \text { - } a_{28}=0.16888, \\
& \text { - } a_{29}=0.1467, \\
& \text { R } a_{1}=07 t 5
\end{aligned}
$$

Rounding of the values of estimators estimators for equation (2) to a number decimal digits of 5 caused acceptable deterioration of the fit less than $0.1 \%$. Reducing number of rounding of decimal digits to 4,3 and 2 causes unacceptable deterioration of the fit as much as: $3 \%, 9 \%, 1216 \%$ respectively.

The coefficients of relatively importance $C_{R I}$ for estimators of equation (1) took following values:

- $C_{R I 1}=410^{7}$,

- $C_{R I 2}=9.710^{6}$,

- $C_{R I 3}=1.610^{6}$,

- $C_{R I 4}=98$

- $C_{R I 5}=233$,

- $C_{R I 6}=42$,

- $C_{R I 7}=293$,

- $C_{R I 8}=2.410^{6}$,

- $C_{R I 9}=49$,

- $C_{R I 10}=41$,

- $C_{R I 11}=4.910^{16}$,

- $C_{R I 12}=150$,
- $C_{R I 13}=12$,

- $C_{R I 14}=3925$,

- $C_{R I 15}=68$,

- $C_{R I 16}=101$,

- $C_{R I 17}=46$,

- $C_{R I 18}=2194$,

- $C_{R I 19}=7750$,

- $C_{R I 20}=71$,

- $C_{R I 21}=385$,

- $C_{R I 22}=476$,

- $C_{R I 23}=49$,

- $C_{R I 24}=137$,

- $C_{R I 25}=15$,

- $C_{R I 26}=341$,

- $C_{R I 27}=40$,

- $C_{R I 28}=595$

- $C_{R I 29}=152$.

The following estimators for equation (2), describing the dependence $D_{H}=f\left(h_{C S}, E_{L}, H B, R_{R}, A_{R}, R_{P}, S_{A T}\right.$, $\left.S_{T T}, R_{R C S}, \mathrm{n}, h_{S E}, G_{F}, d G_{F}, A_{F}, d A_{F}, B_{A}, l_{S S}\right)$ were evaluated:

- $b_{1}=4.30602$,

- $b_{2}=-0.15875$,

- $b_{3}=-41632.23976$,

- $b_{4}=-246.62085$,

- $b_{5}=-1.4886310^{-5}$,

- $b_{6}=-0.05401$,

- $b_{7}=0.04447$,

- $b_{8}=-8.50122$,

- $b_{9}=-0.17005$,

- $b_{10}=8.0416$,

- $b_{11}=-0.02198$,

- $b_{12}=0.83519$,

- $b_{13}=-63.65569$,

- $b_{14}=-0.03694$,

- $b_{15}=-0.14687$,

- $b_{16}=1.70285$

- $b_{17}=0.03377$,

- $b_{18}=8.12981$,

- $b_{19}=0.07385$

- $b_{20}=-1.08859$,

- $b_{21}=0.17004$,

- $b_{22}=0.28044$,

- $b_{23}=0.25544$,

- $b_{24}=0.02633$,

- $b_{25}=21.96488$,

- $b_{26}=5.45599$,

- $b_{27}=2.99612$,

- $b_{28}=-0.6339$,

- $b_{29}=-0.41513$,

- $b_{30}=0.01096$,

- $b_{31}=1.21944$

- $b_{32}=0.72199$,

- $b_{33}=1.34811$, 
- $b_{34}=9.34110^{-4}$,

- $b_{35}=0.22733$.

The number of decimal digits of 5, after rounding estimators for equation (2), causes acceptable deterioration of the fit as much as $0.4 \%$. Reducing number of decimal digits to 4 and 3 , due to rounding, causes unacceptable deterioration of the fit as much as: $22 \%, 1547 \%$ respectively.

Coefficients of relatively importance $C_{R I}$ for estimators of equation (2) took following values:

- $C_{R I 1}=39$,

- $C_{R I 2}=5119$,

- $C_{R I 3}=7275$,

- $C_{R I 4}=0.4$,

- $C_{R I 5}=7$,

- $C_{R I 6}=679$,

- $C_{R I 7}=92$,

- $C_{R I 8}=2.0710^{16}$,

- $C_{R I 9}=2$,

- $C_{R I 10}=692$,

- $C_{R I 11}=2.0710^{16}$,

- $C_{R I 12}=317$,

- $C_{R I 13}=3.4510^{14}$,
- $C_{R I 14}=2364$,

- $C_{R I 15}=23863$,

- $C_{R I 16}=269$,

- $C_{R I 17}=119$,

- $C_{R I 18}=429$,

- $C_{R I 19}=194$,

- $C_{R I 20}=11663.8$,

- $C_{R I 21}=27$,

- $C_{R I 22}=2.110^{16}$,

- $C_{R I 23}=271$,

- $C_{R I 24}=26$,

- $C_{R I 25}=26$,

- $C_{R I 26}=26$,

- $C_{R I 27}=2.110^{16}$,

- $C_{R I 28}=2.110^{16}$,

- $C_{R I 29}=609$,

- $C_{R I 30}=702$,

- $C_{R I 31}=2.110^{16}$,

- $C_{R I 32}=1833$,

- $C_{R I 33}=310$,

- $C_{R I 34}=693$,

- $C_{R I 34}=155$.

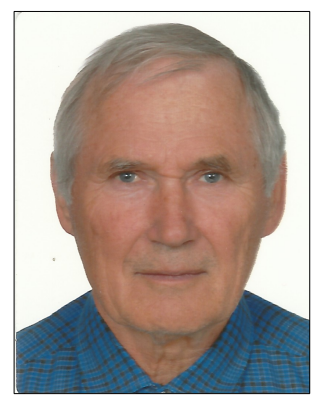

Bolesław Porankiewicz, habilitated in 2005 year at the Agricultural University of Poznań, Faculty of Wood Technology, where he also received his Doctor of Technical Science and the MSc degrees, respectively in years 1973 and 1968. In the years 2008-2011 he was employed as the contract professor at the University of Zielona Góra, Faculty of Mechanical Engineering. Since 2013 guest at Poznań University of Technology, Faculty of Machines and Transportation. Research interest: wood cutting forces, cutting accuracy, wearing of wood cutting tools, construction and exploitation of wood cutting tools and woodworking machinery. 